\title{
Fiscalidad, punición y brujerías. Atacama, 1749 - 1755*
}

Jorge Hidalgo Lehuede** Nelson CAStro Flores ${ }^{* * * *}$

\section{RESUMEN}

Este estudio analiza las características que adquirió el control político de las comunidades atacameñas por parte del corregidor de indios, el que, sumido en la ideología demonológica de la época, en su expresión popular, cree descubrir prácticas de brujería que adquieren un carácter subversivo al afectarlo personalmente. Por intermedio de este proceso judicial

* Este artículo forma parte del proyecto FONDECYT $\mathrm{N}^{\circ} 1960234$ «Historia de los pueblos andinos de Arica, Tarapacá y Atacama: Etnicidades y Conflictos Coloniales», cuyo investigador responsable es Jorge Hidalgo Lehuedé. Resultados preliminares de este trabajo fueron presentados en un Simposio organizado, en el marco de este proyecto, en el Instituto de Estudios Humanísticos de la Universidad de Valparaíso. Quisiéramos agradecer a los profesores y estudiantes los comentarios y críticas que nos formularon en aquella oportunidad. También agradecemos y recordamos una vez más al notable archivista Gunnar Mendoza quien, gracias a su incansable trabajo de descripción documental y a su generosidad, permitió un acceso fácil y rápido a las piezas documentales que encontramos en el archivo que él dirigió tantos años en Sucre. Los documentos que sirven de base a este artículo fueron microfilmados en 1975 y transcritos en Mica. Esperamos publicarlos en un futuro cercano (Nota de Jorge Hidalgo).

** Investigador responsable proyecto FONDECYT $\mathrm{N}^{\circ}$ 1960234. Profesor en la Universidad de Tarapacá. Universidad de Valparaíso, Universidad de Chile.

*** Co-investigador proyecto FONDECYT N 1960234. Programa de Magíster en Historia, Universidad de Chile. conocemos de las prácticas de un significativo número de curanderos y de los conflictos que existían entre aquellos curanderos más prestigiosos y las autoridades étnicas de Atacama.

\begin{abstract}
This paper analyzes the characteristics of political control over Atacaman communities that was exercised by the corregidor of Indians. This official, steeped in the popular demonological ideology of his time, believed that he had discovered manifestations of witchcraft. Because they affected him personally, he found them to be subversive. Through the study of this judicial process, welearn about the practices of a significant number of native healers and the conflicts that existed between the most prestigious of these curanderos and the Atacaman ethnic authorities.
\end{abstract}

\section{Introducción}

Durante la segunda mitad del siglo XVIII, los curanderos de Atacama fueron las víctimas reales de las brujerías y hechicerías de las que eran acusados por el Corregidor y algunas autoridades indígenas. Los acusados debieron sufrir los azotes, las torturas, el encierro, el destierro, la pérdida de sus bienes y uno hasta su propia vida. Estos eran los resultados más patéticos del proceso por brujerías que el Corregidor de Atacama Manuel Fernández Valdivieso había iniciado en septiembre de 1749 , y que había concluido hacia noviembre del mismo año con la sentencia del último de los inculpados. Sorpresivamente el proceso se reabrió en los últimos meses de 1753, ante el arresto de una india que había estado implicada en un maleficio contra el Corregidor, y que se había fugado después de acusar a una de las curanderas procesadas. Se pretendía acumular pruebas contra la curandera que había impulsado este daño, pero ella 
ya había fallecido a consecuencia de los castigos a los que fue sometida durante el proceso.

Completados los hechos, el Corregidor envió a la Real Audiencia el expediente en marzo de 1754. ¿A qué se debió la demora del Corregidor? No pudo deberse a la ausencia de uno de los testigos, porque de todas maneras el Corregidor había dictado ya sentencia. Una aclaración nos viene sugerida por el hecho de encontrarse los expedientes por brujerías junto a los expedientes de la acusación que los indios de Atacama formularon contra el Corregidor hacia junio de 1754, ambos provenientes del Archivo Nacional Boliviano. En la última pieza documental a la que hemos hecho referencia, los testimonios indígenas ponen al desnudo las tácticas punitivas utilizadas por el corregidor para obligar a los indios a la aceptación del reparto de mercaderías, la venta a precios irrisorios de sus propios productos, la usurpación de sus tierras y minas, y para impedir que ellos recurrieran a la Real Audiencia de La Plata para que detuviera los abusos y sancionara la conducta del Corregidor.

Esto último, nos permite sostener que la presentación del proceso por parte del Corregidor respondió a una estrategia destinada a desviar las acusaciones hacia los propios indios, que hasta aquí 110 habían podido recurrir a la Real Audiencia de La Plata, pues el Correddor coercitivamente lo impedía.

Nuestras premisas de análisis serán las siguientes:

1. Hubo una vinculación entre la manipulación de la acusación de brujería y el control de las comunidades indígenas atacameñas ejercido por los dispositivos coloniales hispanos e indígenas.

2. Los dispositivos de control político hispano justificaron el sistema de sujeción de los indios, disponiendo de sus cuerpos y de sus recursos, como una extensión de tácticas punitivas destinadas a controlar y transformar a individuos que hasta aquí habían vivido sin sujeción, entregados a las supersticiones, idolatrías y pactos con el demonio.

A partir de estas premisas, nuestros objetivos serán los siguientes:

1) Determinar los alcances que tiene la acusación de brujerías así como desentrañar su manipulación por parte del Corregidor y la élite indígena.

2) Determinar las distintas perspectivas que sobre la brujería se encuentran en el proceso contra los curanderos atacameños.

3) Verificar la hipótesis sobre los distintos conceptos de brujería que manejaban los funcionarios menores y superiores en el sistema colonial y las propias víctimas (Sánchez 1991)

4) Establecer la ligazón entre brujería, control político y exacciones fiscales.

5) Investigar los procesos de resistencia y de doble articulación.

6) Determinar las formas que adquirió la apropiación de los cuerpos y recursos nativos.

7) Determinar los niveles de conflicto, tanto indígena como hispanos, en los distintos segmentos del poder local atacameño.

\section{El proceso contra brujos y hechiceros en San Pedro de Atacama, 1749}

Hacia septiembre de 1749, una vecina de San Pedro de Atacama solicitó a Juana Antonia, una india curandera del ayllu de Condeduque, que atendiera una confusa enfermedad que padecía su hija Juana Pasquala. Juana Antonia recurrió a los conocimientos que había adquirido desde temprana edad, cuando recorría los alejados lugares del pueblo para encontrar las yerbas, cuyo conocimiento y clasificaciones probablemente había aprendido de su madre Francisca Elvira. Con sumo cuidado habría preparado los elementos para la cura; recogió, en alguna quebrada o vega cercana, cori y preparó con las semillas de algarrobo un brebaje que llamaban en su lengua quilapana. Los efectos curativos de estas hierbas y brebajes, los había observado al aplicarlos a otros pacientes, pero también su uso estaba impregnado de una profunda sacralidad para la comunidad indígena. Lamentablemente, las técnicas curativas empleadas por Juana Antonia no produjeron los efectos esperados. Para explicar el mal biológico que aquejaba a Juana Pasquala, había que acudir a un sistema de interpretación cuya primera víctima sería la propia Juana Antonia.

La gravedad y la confusión que la enfermedad de Juana Pasquala comenzaba a revestir, no pasó desapercibida ante la mirada del Corregidor de Atacama Manuel Fernández Valdivieso:

aviendo acaesido en este dicho pueblo una 
enfermedad repentina a una muchacha española llamada Juana y padesido de este mal mas de un mes con la variedad de opiniones unos de que era pasmo y mas biento en que se le aplicaron varios remedios contra dicho acsidente llegando a terminos de pedir confesion porque le atormentaba vn bulto dentro del cuerpo, y se desia era la madre, y las personas que entendian de ello desian no era tal, por fin en esta confusion de pareseres le dieron los Santos Sacramentos por pedirlo asi dicha enferma y que conosia se moría por los dolores que padesia a todo esto se le allava el pulso bueno sin novedad alguna de que tubiese acsidente natural en que me fue presiso discurrir sobre el particular que sin duda era malefisio como en efecto se a ydo verificando (Autos seguidos por los indios del pueblo de Tacamas provincia de Atajama, contra don Manuel Fernándes Baldivieso, sobre varios maltratanientos. ANB -1754- 58: lv)*.

En el siglo XVIII, quien observaba un cuerpo enfermo centraba la mirada en los síntomas y signos allí inscritos porque ellos hacían transparente la figura de la enfermedad, y ella misma se disipaba en la multiplicidad visible de estos síntomas que significaban su sentido ${ }^{1}$. El conjunto de los síntomas constituía el sistema significante de la enfermedad en la medida que a través de ellos la mirada podía establecer las diferencias, las simultaneidades, o las sucesiones, y las frecuencias. Toda enfermedad tenía un orden natural de síntomas, una manera de sucederse y una manera de determinarse recíprocamente. En otras palabras «todas las manifestaciones patológicas hablarían un lenguaje claro y ordenado» (Foucault,1966: 137). La enfermedad que aquejaba a Juana Pasquala introducía, por el contrario, algunos signos que revelaban una discontinuidad en la sucesión: «se moría por los dolores que padesia a todo esto se le allava el pulso bueno». Sin estos signos discontinuos, el cuerpo convulsionado de la enferma bien pudo haber correspondido a un

* De aquí en adelante será citado como ANB -175458: foja.

1 Respecto a este tema hemos seguido el análisis realizado por Foucault (1966), especialmente el capítulo 6. «acsidente natural» (el pasmo, viento, la madre, o alguna alteración de cólera), como a primera vista concluyeron quienes observaron el cuerpo de Juana Pasquala.

El corregidor debía confirmar su propio juicio recurriendo a la opinión de algunos «especialistas»:

yo dicho Correxidor mande al Alcalde Benito Romero que luego y sin dilasion prendiese y buscase a Diego Andres Moro por haver llegado a mi notisia era el que curava de acsidentes y entendia de pulso y a Domingo Baldivieso natural de este pueblo para el mismo efecto (ANB -1754- 58: lv)

Domingo Valdivieso quien «dixo haver echo el juizio de que pudiere ser algun ayre o alternasion de colera» (ANB -1754- 58: 4r), rápidamente debió cambiar sus conclusiones porque una observación más atenta del cuerpo de la enferma hacía visible un conj unto de síntomas cuyo significado era imposible leer con claridad, de modo de remitirlos a alguna enfermedad conocida:

continuando en casa de la enferma llamada Juana española la vio varias vezes aogada y querido bolbia en si desía le venian a la garganta dos bultos que la querían matar y le serraban las fauses y boca y no podia tragar cosa alguna ni aun el agua y que ya empeso a discurrir era malefisio (ANB -1754- 58: 4r)

Esta misma situación la había confirmado el curandero Diego Cruz Moro que «alló en su conciensia estar malefisiada y que tenía dentro del cuerpo alguna cosa porque le tocó y reconosió pasava para un lado y otro» (ANB -1754- 58: 2r). Cruz Moro aplicó a Juana Pasquala, al igual que lo había hecho anteriormente Juana Antonia, «varios remedios y no le hicieron efecto y que por el pulso que lo hallaba siempre natural como de vn sano conosió ser malefisio» (lbídem: 2v).

La presencia de un pulso bueno, en un cuerpo alterado por una confusa enfermedad, evidenciaba el hecho de que no se trataba de un accidente natural. Había que encontrar un elemento que despejara la incertidumbre sobre la enfermedad de Juana Pasquala, y ordenara los signos de modo de remitirlos a un orden no-natural, como al parecer correspondían los síntomas del cuerpo enfermo. Los dos «especialistas» llamados por el corregidor Fernández reconocieron, cada uno a su turno, la existencia de un 
elemento exógeno que se encontraba depositado en el interior del cuerpo de Juana Pasquala y que constituía el referente adecuado para diagnosticar un accidente introducido con el claro propósito de dañar a la enferma.

Una vez que se despejaron las dudas sobre la naturaleza de la enfermedad que aquejaba a la española, era necesario proceder a su curación. El curandero Diego Cruz Moro no pudo romper el daño causado, pero al tratarse de un accidente introducido sólo podía ser explicado a partir ele la eficacia del procedimiento efectuado y a la fineza de quien lo había realizado. Como era evidente que Juana Pasquala había sido víctima de un maleficio, la tarea que se imponía al Corregidor era la de encontrar al hechicero, establecer los motivos del daño provocado y, eventualmente, obligarlo a describir el procedimiento para que los curanderos o él mismo procedieran a deshacer el daño.

Las miradas acusadoras se dirigieron contra Juana Antonia, la india del ayllu de Condeduque, que había sido solicitada para curar a la española enferma. Los especialistas llamados por el Corregidor, Diego Cruz Moro y Domingo Valdivieso, declararon que la propia:

enferma le había dicho y declarado haver visto entre sueños a vna yndia natural de este pueblo llamada Juana Antonia hixa de Pascual Morales y de Francisca Elbira de el ayllo de Condeduque, que este venia y le havia yntrodusido vnos atados de cabellos en la boca sin poderse defender (ANB -1754- 58: $2 \mathrm{v})$.

El corregidor ordenó a los alcaldes indígenas que detuvieran a la curandera y la encerraran «en un quarto y llegado la noche la castigó y ostigada de los crueles asotes que dieron confesase si era bruja y dixo en su confesión que si era bruja» (ANB -1754-58: 25r). En su confesión ella debió haber afirmado que era curandera y que entendía de daño, pero el intérprete que ella misma solicitó bien pudo describir los procedimientos de acuerdo a lo que se pensaba era un procedimiento de hechicería. Reconoció «que desde chiquita tenía echo pacto con el demonio» (ANB -1754- 58: 3v), lo que equivalía a confesar en la época, que el conocimiento de tratar enfermedades le había sido otorgado por un pacto con el demonio en el que colocaba como precio su alma (Yauri 1994: 240; Flores 1985: 58-71). La india habría causado el maleficio por envidia (ANB -1754- 58: 3r), y «en quilapana le havíadadodos vezes por arte de bruxerías como que tenía pacto con el Demonio desde criatura» (ANB -1754- 58: 4v).

Hay una doble violencia en las declaraciones hechas por Juana Antonia: fueron arrancadas por el encierro y los azotes, para ser violentadas en la interpretación que de ellas hizo su intérprete, el gobernador indígena Francisco Ziari. Es obvio que Juana Antonia no hablaba el español y que requería, en consecuencia, de un intérprete para prestar declaración, que en este caso fue la máxima autoridad indígena de San Pedro, quien, a su vez, por su dependencia del Corregidor y sus propias ideas traduce y «traiciona» a la declarante. Ziari, situándose en el mundo de las representaciones hispanas fue describiendo la acción de curandería realizada por Juana Antonia, resignificándola en el «arte de bruxerías». Las declaraciones, a medida que iban siendo traducidas, fueron decodificadas a partir de un sistema de interpretación que circunscribía ciertas prácticas indígenas en la idolatría y en el pacto con el demonio. Además, el intérprete contaba con un hecho adicional cual era la ambigüedad que tenía el propio curandero en el mundo indígena, derivado de su facultad para provocar daños, del mismo modo que podía deshacerlos y curar enfermedades. De este modo, podríamos comprender que el uso de brebajes y de hierbas, como los utilizados por Juana Antonia, tendría un doble propósito: 1) como un medio para introducir algún elemento que provoque daño al organismo y genere un debilitamiento del afectado y; 2) como un medio para limpiar el organismo de elementos introducidos para provocar daño (Cf. al respecto Yauri, 1994: 237). No obstante, en tiempos pre-coloniales, estos procedimientos no estaban asociados a «conspiraciones maléficas» (Silverblatt 1990: 128) y a una simbólica del mal de raíz judeocristiana.

Es posible que la operación realizada por Juana Antonia haya correspondido a un procedimiento de limpieza del cuerpo dañado. Porque, en ningún momento de su declaración, ella expresó los motivos de la envidia que la llevó a causar un daño a Juana Pascuala. Tampoco el corregidor Fernández se tomó la molestia de preguntárselo a la acusada. Sólo bastaba que las torturas le hicieran declarar que había actuado motivada por la envidia pura encontrar en ésta la causa del daño que aquejaba a la maleficiada Juana Pascuala. Más allá de estos motivos, creados por un estado de alteración, como el que padecía la enferma, y las confesiones de una mujer cuyo cuerpo no podía dejar de ocultar las huellas de los azotes y 
la pesadumbre del encierro, lo único cierto es que Juana Antonia concurrió a la casa de la enferma para proceder a su curación, dándole de beber quilapana junto con las hierbas que ella había prescrito para tratar el daño. El que Juana Pascuala haya visto en sueños a la india curandera introduciéndole «un atado de cabellos», reafirma dos hechos: que sí estuvo presente Juana Antonia en la casa de la enferma y que le dio algún purgante para expulsar el daño que había en su cuerpo, que en su delirio confundió con el «atado de cabello».

Lentamente las confesiones de la acusada curandera iban dibujando los contornos de un fenómeno impreciso, cual es el del maleficio y su vinculación con prácticas demoníacas, pero que ocupaban un lugar central en las representaciones coloniales sobre la enfermedad. La enferma se siente maleficiada y esta creencia suya y de quienes la estaban tratando, adquiere realidad en la mirada que dirigen a su convulsionado cuerpo y en las declaraciones de la propia hechicera.

El curandero indígena, que había ordenado llamar el Corregidor, fue incapaz de deshacer el daño que padecía la enferma. Pero el Corregidor contaba con la ventaja de tener bajo su control a la supuesta bruja y «persuadiendole a que la sanase ofresio aserlo dentro de tres días que buscaría remedios y lo aría en compañía de una india Cruza de Sequitur quien se hallava presente por haber dicho la referida yndia Juana que con ella havía echo el daño» (ANB -1754- 58: 3r). Sólo si sus prácticas curativas resultaran eventuahnente ineficaces, la inculpación de otra mujer, la india Cruza que había estado presa en otra oportunidad por provocar daño (ANB -175458: $3 \mathrm{v}$ ), podía ofrecer a la curandera la posibilidad de hacer de aquélla la responsable principal del daño.

La curandera procedió a la limpieza interior del cuerpo de Juana Pasquala, no sin antes «refregarle desde la garganta y el pecho y se fueron baxando los dichos bultos» (ANB -1754- 58: 3r), como antes lo

2 Puede haber una correspondencia entre esta expresión y el quechua qora, hierba (Comunicación del profesor Gilberto Sánchez). Para un análisis más acabado de las hierbas y brebajes utilizados en Atacama, veáse Castro (1997).

3 De aquí en adelante será citado como ANB -1764131: foja. había hecho con otros clientes y con la propia enferma:

por la experiensia que tiene de haver visto echar animales y otras ynmundisias del cuerpo le dio un bomitorio com parecer de dicho señor corregidor y luego al punto echo vn atado de cabellos bien liados el cual le quemó y luego al otro día le asegundo el bomitorio $\mathrm{y}$ volvio a echar otro como el primero y desatandolo allo un palito llamado cori ${ }^{2}$ en la lengua (ANB -1754- 58: 4r)

Aquí cabe hacer una observación que parece importante para comprender el cruzamiento de discursos, la mixtura de sistemas de referencia con la que se está actuando para mirar el cuerpo de la enferma: de una parte, una representación «moderna» de la enfermedad, como es el que reconoce una sintomatología de la enfermedad centrada en el cuerpo, que revela un orden natural de la propia enfermedad; de otra, un discurso tradicional que describe una sintomatología que se inscribe en un nivel metasomático, como es del accidente introducido o maleficio y que es causado por la envidia. Es esta última representación la que utiliza Juana Antonia, como hemos señalado más arriba.

El cori podía ser un eficaz medio para expulsar el daño, por eso la curandera lo había utilizado para preparar el vomitorio, pero en la declaración es localizado como el causante del dañó: «desatándolo allo un palito llamado cori en la lengua». En estos momentos se estaba confirmando las facultades que tenía todo curandero para hacer y deshacer daños, pero también el hecho que podría ser «los ynstrumentos e cauza de todo mal», tal como lo señalaban las Instrucciones de Toledo («Instrucción y ordenanzas hechas por el virrey don Francisco de Toledo para los corregidores de indios, 1574» ANB -1764- Expedientes coloniales $N^{\circ} 131:$ 780-123) ${ }^{3}$.

Para el Corregidor, las evidencias que se habían acumulado contra Juana Pasquala eran suficientes para demostrar tanto su calidad de bruja como su pacto con el demonio. Con estas confesiones él podía proceder a su castigo, por lo que el Corregidor ordenó en un auto de destierro que «dentro del término de tres días salga la referida yndia Juana con pena de destierro de los términos de esta provincia por un año» (ANB -1754- 58: 5r). Juana Antonia debía ser entregada al estanciero Zenón Zuleta para que la llevara «a su estancia de el Paposo jurissión de Santhiago de Chile quien se obligó a asegurarle y 
entregarla cumplido el término de su destierro» (ANB -1754- 58: 5v). Pero cuando se realizaban los preparativos para desterrar a la curandera, una nueva acusación vino a complicar su situación y, esta vez, la de su propia familia.

Ante un recrudecimiento de la enfermedad de Juana Pasquala, la madre se vio obligada a llamar a Domingo Valdivieso. Nuevamente los signos revelaban una alteración de los síntomas, el estado en que se encontraba la enferma se contradecía con el buen pulso que se observaba. Para terminar con los ahogos que aquejaban a la enferma, Domingo Valdivieso le dio, probablemente, el mismo vomitorio que días atrás había preparado Juana Antonia, y que había demostrado ser eficaz. Si fue éste u otro el vomitorio empleado por Valdivieso es cuestión que poco importa, lo cierto es que produjo el mismo efecto que el obtenido por la curandera Juana Antonia:

\section{haviendole dado tersera vez el bomitorio en presencia de dicho señor Corregidor echo la enferma otro atado de cabellos mayor que los primeros con tres puntas echos nudos todos ellos mui liados lo que se mostro a varios y al padre Maestre Fray Domingo Estupiñan quien se alla en este pueblo (Autos..., -1754- ANB 58: 6r).}

Al sobredimensionar el daño que Juana Pasquala padecía, expulsándole un «atado de cabellos mayor que los primeros», que mostró al cura y al Corregidor, Domingo Valdivieso no estaba haciendo otra cosa que dejar en evidencia su propia capacidad para deshacer daños. No obstante, como la preparación del vomitorio fue probablemente el mismo que había utilizado Juana Antonia, para deshacer el supuesto daño que ella había provocado, debía tratarse de un tercer maleficio provocado por la misma curandera.

Los nuevos ahogos de Juana Pasquala, significaron, para la curandera de Condeduque, volver a sufrir los mismos azotes que había tenido que soportar en sus anteriores declaraciones. El gobernador Francisco Ziari fue llamado para que sirviera de intérprete en una declaración en la que la curandera tuvo que reconocer su participación como responsable de este tercer maleficio. Para el Corregidor esta situación dejaba entrever la posibilidad que la curandera no actuaba sola. De un modo u otro, ella debía contar con otros asistentes que la proveyeran de los implememos necesarios para provocar el daño, máxime si el encierro la imposibilitaba como para que ella los recolectara. Tal como el solo ruido de los azotes cohdicionabm las reacciones y las pulsaciones de su maltratado cuerpo, el corregidor podía obligar a la debilitada imaginación de la india Juana Antonia el pronunciamiento de un determinado nombre:

dixo que un hombre le havia dado aquellos tres atados para que le diese a la enferma y que no lo conosia y bolbiendo a yntarle respondio que dos del pueblo de Toconao le havian ayudado y que no los conosia a lo que se le replico disiendo no podia dexar de conoserlos (ANB -1754- 58: 6v)

Desesperadamente la curandera Juana Antonia trataba de disminuir su participación en el maleficio, responsabilizando a tres individuos desconocidos. Pero el corregidor pedía que los identificara; sólo así podría arrestarlos y obligarlos a declarar. Por lo demás, el Corregidor no esperaba cualquier nombre, contaba con el testimonio de la propia enferma que «desia haverla visto con su madre de la dicha yndia llamada Francisca Elbira». Sólo el encierro y los azotes pudieron obligar a Juana Antonia a involucrar imaginariamente a su madre en un no menos imaginario hechizo: «Respondio por fin que con su madre havia echo» (ANB -1754- 58: 7r). Francisca Elvira fue detenida, según propio testimonio dirigido al Fiscal protector, «en la cartel despues de castigarme tendida en una escalera luego me pasó a la dicha cancel y a los tres dias dispuso mi destierro» (ANB -1754- 58: 25r).

Individuos tan peligrosos como Juana Antonia y su madre debían ser desterrados de los términos de la Provincia de Atacama «por toda su vida o el tiempo que me mantubiere de Corregidor en dicho su destierro» (ANB -1754- 58: 7r). El destierro contra las indias se legitimaba en esa lógica del dominio y control planteada, en el siglo XVI, por las Instrucciones de Toledo, y que articulaba una racionalidad del orden y la policía y desde la cual se podían comprender las tácticas punitivas. El hecho que la acción dañina estuviera siendo dirigida hacia los miembros hispanos de la sociedad colonial, demostraba cuán débiles eran los mecanismos de control y cuán necesario era someter a los indios bajo un riguroso sistema de sujeción.

Una sobredeterminada representación del indio articulaba esta sentencia: «su menos resistencia a las tentaciones» (ANB -1764- 131). De ahí que la sentencia se dirigiera a otros individuos que aún permanecían en los márgenes del cuerpo social, quizás otros posibles brujos y hechiceros. La demarcación 
de lo ilícito permitía localizarlos y distribuirlos, junto con hacerlos objetos de exclusión no del cuerpo social, porque desde el momento mismo en que estaban sumidos en las «supersticiones y pacto con el demonio» quedaban fuera de él, sino de los propios márgenes que las relaciones de poder habían dibujado.

El auto de destierro contra Juana Antonia y su madre previó que si ellas se negaban a obedecer la sentencia o si fueran ayudadas por otros sujetos, éstos serían acusados «por ynnobedientes al juez y comprehendidos en el mesmo delito» (ANB -175458: 7r).

La acusación de hechicería contra Juana Antonia y su madre, puso al desnudo también la frágil situación a la que quedaban expuestas sus propias personas, sus bienes y el círculo más estrecho de parientes. Los años y la mala salud no jugaron a favor de Francisca Elvira, no pudo llegar siquiera al despoblado en el que debía cumplir su sentencia de destierro: «caminando beinte leguas me dexaron y estube seis meses en los cerros pasando mil necesidades y trabajos» (Autos..., -1754- ANB 58: 25r). Mientras tanto sus sementeras se secaban, perdiendo las siembras con las que debía subsistir y cuyos productos intercambiaba entre sus parientes y amigos. Los efectos del proceso y de la acusación también alcanzaron a sus dos hijos varones, «el uno hera cantor y el otro tasero handuvo fujitivo el cantor ha dejado su muger hijos y no se sabe donde para que también lo puso preso en la cárcel de cabesa en el sepo y estando para castigarlo se le hincó de rodillas y lo perdonó» (ANB -1754- 58: 25r).

\section{LA BRUJERIA: EL MICRO ESPACIO DEL CONFLICTO}

Con el juicio y las declaraciones de Juana Antonia la brujería había ido cobrando realidad, observándose el peso real del imaginario de la hechicería: se

4 El hacer visible el daño en la forma de un objeto reconocible como el «atado de cabellos», evidencia las capacidades del curandero, la eficacia simbólica de sus técnicas curativas, además de entregar 'materialidad' o 'huellas positivas' a un sistema (le interpretación del mal biológico, como es el daño, que regularmente parecía contentarse con el reconocimiento verbal del daño (Cf. Lévi-Strauss, 1994). dibujaban sus procedimientos, la eficacia de éstos para causar daño, sus lazos con las supersticiones y su pacto con el demonio; pero sobre todo se localizaba a los agentes de tales males, los curanderos convertidos por el poder de la representación en hechiceros o brujos. Las dos indias desterradas eran la muestra de un espectro más amplio de brujos y hechiceros que recorrían y poblaban los ayllu, los pueblos y los demás términos de la provincia de Atacama.

Si bien la acusación contra Juana Antonia y su madre había procedido de la propia enferma, el Corregidor tuvo la preocupación de que fuera escuchada por otros testigos y que el maleficio fuera confirmado por dos especialistas que curaban de accidentes y que entendían de pulso, es decir, que compartían con aquéllas el conocimiento de las prácticas curativas. Esto último silencia una historia lo bastante compleja como para desplegar cada uno de los pliegues que conformaron el entramado de conflictos y tensiones entre curanderos. No obstante, es plausible sostener que, al reafirmar la presencia del daño y actuar como testigos de oídas en la identificación de Juana Antonia como la causante de éste, los dos especialistas tenían el sumo interés de identificarla por tres motivos: primero, porque como curanderos ellos también estaban expuestos a ser acusados de hechicería; segundo, porque al acusar a Juana Antonia podían librarse de una competente rival; y tercero, habiendo establecido que era un maleficio, ellos podían aplicar sus técnicas para deshacer el daño, de modo de aumentar su prestigio y las redes de clientes. Esto último queda de manifiesto en la actuación de Domingo Valdivieso, quien estuvo muy ligado a la acusación contra Juana Antonia y a la que se hizo contra su madre, además, fue él quien continuó el tratamiento del daño, aplicando aquel vomitorio con el que expulsó del cuerpo de la enferma un objeto de mayor proporción que el de los dos anteriores expulsados por la curandera ${ }^{4}$.

Por otra parte, para algunos miembros de la élite indígena, el proceso iniciado por el Corregidor, era una buena oportunidad para determinar las fuentes de los desequilibrios que en el último tiempo habían estado afectando a la comunidad indígena. Enfermedades, muertes repentinas o pérdidas de animales, se sumabas a estos desequilibrios y que tenían por principales víctimas a algunas autoridades indígenas o a sus familias.

El gobernador Francisco Ziari acusó a Diego Cruz Moro de «que era publico en toda la provincia ser maestro de bruxerias por el miedo y terror que le 
tenian todos de tal suerte que el que llegaba a tener con el algun encuentro lo enfermaba sino lo mataba» (ANB -1754- 58: 7v). La insistencia de Francisco Ziari en que Diego Cruz Moro era un «maestro de bruxerias por el miedo y terror que le tenian», expresa un segundo nivel en el que la acusación de brujería silencia un conflicto entre la figura del curandero y la del gobernador indígena. Considerando que se había aplicado una pena de destierro a las dos curanderas, de confirmarse la acusación de brujería contra Diego Cruz Moro podría correr la misma suerte, de modo que el gobernador se vería libre de tan molesta figura.

La mala relación entre ambas figuras se originó en una venta de jumentos que el gobernador Francisco Ziari había hecho a Diego Cruz Moro y que éste se había negado pagarle:

y recombiniendole por ellos y que se los pagase porque de lo contrario havia de poner demanda ante el corregidor sin más motibos que este en brebes dias se sentio enfermo este declarante y con esta malisia hiso llamar a dicho Diego y le ropo lo curase como con efecto le curo y despues se le murieron dos hixos un baron y una muger (ANB -1754- 58:

$7 v)$

El Corregidor acogió prontamente la acusación del gobernador Ziari. Diego Moro fue apresado y colocado en el cepo de la cárcel. Fernández Valdivieso, quien en un corto tiempo había probado las técnicas para obligar a algún acusado a declararse culpable, no sin antes detallar sus delitos, ordenó «sacar de el cepo lo hise hacer la Señal de la Cruz y prometio desir verdad de lo que supiere y le fuere preguntado» (ANB -1754- 58: 8r). Contraviniendo las normas más elementales del derecho de la época, el Corregidor nombró a Francisco Ziari como intérprete, en un proceso en el que él era el acusador. Entonces, según Ziari, Diego Cruz Moro reconoció ser el causante de la enfermedad y de la muerte de los hijos del gobernador, así como de otros daños cuya relación puede observarse en la siguiente tabla:

\begin{tabular}{|c|c|c|c|}
\hline VICTIMA & PROCEDIEMIENTO & MOTIVO & COMPLICES \\
\hline $\begin{array}{l}\text { Pedro alcalde del } \\
\text { ayllu Solo }\end{array}$ & Daño, muerte & $\begin{array}{l}\text { Le había dado dos } \\
\text { lazazos }\end{array}$ & \\
\hline $\begin{array}{l}\text { Gobernador } \\
\text { Francisco Ziari }\end{array}$ & $\begin{array}{l}\text { Daño enfermedad } \\
\text { repentina }\end{array}$ & $\begin{array}{l}\text { Iba a recurrir al } \\
\text { Corregidor para } \\
\text { obligar al curandero } \\
\text { a pagarle dos jumentos }\end{array}$ & \\
\hline $\begin{array}{l}\text { Dos hijos varones } \\
\text { del gobernador Ziari }\end{array}$ & Daño y muerte & $\begin{array}{l}\text { Venganza contra el } \\
\text { padre }\end{array}$ & \\
\hline Andrés Pardo & Daño y muerte & $?$ & $\begin{array}{l}\text { Fue un daño comenzado } \\
\text { por su mujer }\end{array}$ \\
\hline $\begin{array}{l}\text { Melchor Reyes, } \\
\text { hermano del Cacique } \\
\text { de Betere }\end{array}$ & $\begin{array}{l}\text { Daño: enfermedad } \\
\text { y muerte de una } \\
\text { yegua }\end{array}$ & $?$ & \\
\hline Juana Antonia & Daño y enfermedad & $?$ & $\begin{array}{l}\text { Con su mujer y una india } \\
\text { llamada Santusa del ayllu } \\
\text { de Sequitur, continuó con } \\
\text { el maleficio causado por } \\
\text { Juana Antonia }\end{array}$ \\
\hline $\begin{array}{l}\text { Cinco víctimas } \\
\text { fuera de la provincia. }\end{array}$ & Muerte & Indeterminado & \\
\hline
\end{tabular}

-Tabla 1 Fuente: ANB -1754- 58: 8r-9r. 
A esta lista de daños, Diego Cruz Moro entregó una lista de hechiceros que abarcaban varios puntos de la provincia, identificando algunos de sus delitos y el grado de conocimiento que tenían de las prácticas de hechicería (fino, asistente), como podemos observar en la siguiente tabla:

\begin{tabular}{|c|c|c|c|}
\hline HECHICERO & LOCALIZACION & DELITO & OB SERV ACION \\
\hline Juana Antonia & Condeduque & $\begin{array}{l}\text { Maleficio contra } \\
\text { Juana Pascuala }\end{array}$ & \\
\hline Viuda Francisca Elvira & Condeduque & $\begin{array}{l}\text { Maleficio contra } \\
\text { Juana Pascuala }\end{array}$ & \\
\hline Santusa & Sequitor & $\begin{array}{l}\text { Maleficio contra } \\
\text { Juana Pascuala }\end{array}$ & \\
\hline $\begin{array}{l}\text { María } \\
\text { (madre de Santusa) }\end{array}$ & Toconao & $\begin{array}{l}\text { Maleficio contra } \\
\text { Juana Pascuala }\end{array}$ & $\begin{array}{l}\text { Asistente en } \\
\text { Toconao }\end{array}$ \\
\hline $\begin{array}{l}\text { Ollera Juana } \\
\text { Vieja Juana Shatalina }\end{array}$ & Condeduque & & \\
\hline $\begin{array}{l}\text { María Rosa (nieta de } \\
\text { Juana Catalina) }\end{array}$ & Toconao & & \\
\hline $\begin{array}{l}\text { Juana (hermana de } \\
\text { María Rosa) }\end{array}$ & Toconao & & \\
\hline Cruza & Sequitor & & Hechicera fina \\
\hline Ana (criolla) & López & & \\
\hline $\begin{array}{l}\text { Roque el viejo } \\
\text { Ciego }\end{array}$ & Toconao & $\begin{array}{l}\text { Mató al cacique } \\
\text { Agustín Fabiáui } \\
\text { y su mujer }\end{array}$ & Hechicero fino \\
\hline Viuda Pasquala & Calama & & Asistente en Calalna \\
\hline \multirow[t]{2}{*}{ María } & Calama & $\begin{array}{l}\text { Mató un hijo de } \\
\text { Balthasar arrojándole } \\
\text { un muñeco al cuerpo }\end{array}$ & \\
\hline & & $\begin{array}{l}\text { Maleficio contra } \\
\text { Juana }\end{array}$ & $\begin{array}{l}\text { Esposa de } \\
\text { Diego Cruz Moro }\end{array}$ \\
\hline María Micaela & Betere & $\begin{array}{l}\text { Pascuala. Inició el } \\
\text { daño que causó la } \\
\text { muerte a Andrés } \\
\text { Pardo. Posterionnente } \\
\text { se le acusó de un } \\
\text { intento de maleficio } \\
\text { contra el Corregidor. }\end{array}$ & Hechicera fina. \\
\hline
\end{tabular}


Dos cuestiones deben ser aclaradas a partir de esta tabla. Primeramente, aunque en su gran mayoría, son mujeres las identificadas por Cruz Moro como hechiceras, esto no permite un análisis del problema en términos de relaciones de género. Silverblatt ha señalado, con demasiada insistencia, la relación mujer-bruja con una concepción patriarcal del orden social, en la que ésta fue subordinada transformándose en su mayor enemiga (Silverblatt 1990: 124 y ss.). Un rápido análisis de la documentación que se dispone sobre procesos coloniales, realizados por prácticas de hechicería, tiende a matizar estas categóricas afirmaciones. A nuestro juicio, la identificación de algunos hechiceros como viejos, ciegos o viudas sigue los estereotipos coloniales de las cualidades que permitirían localizar a cualquier hechicero, independientemente que fuera hombre o mujer. La valoración radicada más en el orden de los defectos físicos o sociales, o en lo que éstos tienen de desviación con respecto a un sistema considerado como normal, que en consideraciones sexistas.

La doble calidad de acusador e intérprete, puede colocar bajo sospecha la interpretación que Ziari hizo de la declaración de Diego Cruz Moro. No obstante, y aunque hubiera habido ciertos grados de «falsificación», la declaración está interpretada en una doble perspectiva: como traducción desde el campo semántico indígena al hispano, y como interpretación de los hechos declarados, que se referían a enfermedades y muertes practicados por el propio curandero y una red que se extendía por toda la provincia, de acuerdo a una lógica indígena del

5 En un trabajo al ya hemos hecho referencia, Malengreau sugiere que cualquier desorden social que escape a la autoridad, en nuestro caso a la autoridad indígena, puede ser atribuido «a individuos que se consideran al margen de la sociedad, de los que se sospecha y hasta se acusa de actuar en contra del mundo reconocido de las instituciones. Esos individuos pueden ser cualquier ciudadano en conflicto abierto con la autoridad, pero más a menudo son personas más potentes que otras autoridades subalternas que se oponen a sus superiores. En este caso, la autoridad superior puede tratar de descalificar socialmente al individuo o a la autoridad subordinada frente a la opinión pública al acusarlos de brujería» (Malengreau 1994: 277). daño. Habíamos sostenido más arriba que en el diagnóstico de la enfermedad de Juana Pascuala se habían cruzado dos sistemas de referencia, uno «tradicional» y uno «moderno». La diferencia de ambas concepciones estriba en la manera en cómo diseñan el campo de lo patológico, una a partir de la descripción y compilación de los síntomas a partir de una observación del cuerpo enfermo, la otra a partir de una narrativa que localiza la generación. del daño en un espacio metasomático, en circunstancias locales, temporales y sociales (Cf. al respecto Sánchez 1992: 62, 64). En este sentido, las relaciones personales, o mejor dicho el universo relacional en el que se inscribe la enferma, constituye una suerte de matriz significante a partir de la cual pueden cobrar sentido los daños que una persona sufre (Cf. Malengreau, 1994: 253-283; también Sánchez 1991: xxx-xxxii). Esta matriz opera como un mecanismo de explicación, identificando, en el contexto de las relaciones del afectado, a aquellos sujetos que, potencialmente y por diferentes motivos, podrían provocar daños: la envidia de Juana Antonia explica el daño que sufre Juana Pascuala, Diego Cruz Moro enferma al gobernador Ziari o mata a sus dos hijos para evitar ser acusado ante el Corregidor, lo mismo que mata al cacique del ayllu Solo por venganza. A juzgar por el registro etnográfico, esta manera de localizar la etiología de la enfermedad en las vicisitudes o accidentes que atraviesa el individuo dentro del cuerpo social, parece ser aún predominante en comunidades andinas contemporáneas (Cf. Sánchez 1992: 65).

Hasta antes de las declaraciones de Diego Cruz Moro, como lo hemos mencionado, una serie aislada de enfermedades y muertes, había provocado cierto desconcierto entre la población indígena de Atacama. Una vez que Diego Cruz Moro hubo confirmado su participación en tales daños identificando a varios de sus causantes, el gobernador Ziari lograba restablecer un desequilibrio que si bien no había afectado al conjunto de la comunidad indígena, sí afectó a algunas autoridades indígenas y sus parientes, entre los que se encontraba el propio gobernador Ziari ${ }^{5}$.

El conflicto entre Ziari y Moro permite cuestionar la imagen tradicional del curandero profundamente ligado a los procesos de reproducción de los equilibrios y solidaridades internas (Cf. al respecto Van Kessel 1993). Otros autores han destacado el manejo y control que los kurakas ejercían directamente sobre las prácticas rituales, en un intento por vincular, de una parte, religión y poder político indígenas durante el período colonial (Millones 1984), y, de otra, la vinculación entre 
ritualismo local y resistencia frente a las presiones tributarias (Salornon 1990). No hemos encontrado información alguna que tienda a confirmar estas interesantes proposiciones. Por el contrario, la actitud del gobernador Ziari se compara con la que asumió la elite indígena atacameña en la campaña de extirpación de idolatrías realizada por el visitador Francisco de Otal durante el siglo XVII, en la cual sirvieron como testigos en contra del proceso que éste inició contra varios especialistas religiosos acusados de «idólatras» (Castro 1997).

No obstante, existe un elemento interesante en un trabajo de Millones (1976) que es necesario considerar. Aunque sigue la misma línea de su posterior trabajo, la documentación que utiliza pone de manifiesto que la intervención de los hechiceros adquiere protagonismo dependiendo del grado de autoridad que tenían las estructuras políticas indígenas. Es decir, que la acción del hechicero se hacía a expensas del menoscabo de la autoridad indígena. Como veremos más adelante, es posible que la fragilidad y discontinuidad de la estructura de autoridad indígena, adquirida por su dependencia del Corregidor, hayan permitido a los curanderos representar, por lo menos en este período, una estructura de poder, si bien marginal con respecto a los dispositivos coloniales, pero con una mayor continuidad e influencia que éstos dentro de amplios segmentos de la población indígena. Esto permitiría comprender el especial interés del Gobernador Ziari por identificar a Diego Cruz Moro con un «maestro de bruxerias» y de acusarlo de ser el causante, junto con otros curanderos, de la serie de desequilibrios y maleficios que habían afectado al Pueblo de San Pedro.

Luego de la «declaración echa por el reo Diego Cruz Moro y la ynformasión echa de los delitos en que a yncurrido», el Corregidor ordenó y mandó:

al governador y cazique de esta provinsia que dentro del termino de tres días saquen a dicho reo y concfusgan a la Villa de Potosi y entreguen en la Casa de Moneda en donde se mantendrá por todo el tiempo de su vida sin

6 El único dato que tenemos de otras detenciones es el referido por el alcalde Fernando Araya quien declaró haber detenido a «dos mugeres que por bruxas le havía mandado traer dicho Correxidor» (ANB 58: 14v). que tenga facultad de poder salir con pretesto

alguno (ANB 58: 9v)

La racionalidad del castigo, al igual que había sucedido en el caso de las otras curanderas acusadas de brujerías, se justificaba en el riesgo que podían correr los habitantes por la mala inclinación de Diego Cruz Moro. No obstante, Diego Cruz Moro representaba, por el hecho de ser un «maestro de bruxerías», un riesgo mayor al de las dos curanderas, lo que también justificaba el hecho que cualquier intento de fuga sería fuertemente reprimido con la pena de muerte (ANB 58: 10r).

De los seis daños provocados por Diego Cruz Moro en la provincia, cinco habían sido dirigidos hacia los dispositivos indígenas de control colonial, o en su defecto a los miembros de sus familias. El daño causado contra una española, en el que participaba una red de hechiceros, podía ser el inicio de una escalada dirigida contra la totalidad del cuerpo social atacameño. La extensión geográfica que ocupaban los denunciados brujos pudo haber imposibilitado su detención, lo que explicaría que el Corregidor no haya incluido sus declaraciones en los expedientes formulados contra los ya confesos hechiceros ${ }^{6}$. Sólo conocemos la situación que vivió uno de los inculparlos, María Micaela, esposa de Diego Cruz Moro y a quien él mismo había delatado.

Diego Cruz Moro había participado en el proceso contra Juana Antonia declarando que «haora últimamente queriendo curar a una enferma alló ser la malechora la yndia Juana Antonia» (ANB 58: 8v). La mujer de Diego Cruz Moro también era curandera, por lo que al parecer concurrió a la casa de la enferma para ayudar a su marido en el tratamiento del daño. Esta posición de la mujer encajaba bien en la acusación realizada por Diego Cruz Moro:

haciéndole cargo que era brujo, y por tal te tengo, y lo empesó a castigar con azotes, y lo tenía con grillos mui maltratado todo el cuerpo con los azotes, y viéndose obstigado con tales tratamientos de rigor de los azotes, dijo al Correxidor mi mujer es bruja yo no soi y por los azotes y de miedo cargó a su mujer (ANB 59: 26r)

En los autos proveídos por el Corregidor sobre los delitos de brujerías no encontramos declaración alguna hecha por María Micaela, únicamente tenemos la declaración de testigos que presenciaron o escucharon los castigos a los que sometió el corregi- 
dor a esta mujer. Juan de Araya, que había sido juez y alcalde de indios en 1749, declaró años después en un juicio contra el Corregidor Fernández Valdivieso que:

se halló muy compadecido del rigor del corregidor del suseso de la ynfeliz yndia mandó traer a María Micaela muger de diego Crus y luego al punto mando tender en una escalera, mandó, asotar muy rigurosamente con mucha humanidad pues no fueron estos azotes solo una bes sino nobenario, por todas las noches pribándole de que no le den de comer ni agua y la pobre pidiendo a gritos por la Sangre de Dios que le den un jarro de agua y a escondidas le alcanzaba la mitane $=$ y la tenía enserrada a día y noche en un quarto oscuro con un par de grillos y esposas pretestando, ser bruja, y no con otra causa más que lo referido, y que es sierto y notorio a todos de este pueblo, que de estos tan rigurosos, asotes se le hicieron una llaga por donde se le salieron las tripas que después de esto la inbió desterrada dicho Corregidor al pueblo de Chiuchiu donde llegando luego a los tres días o quatro murió la ynfelis muger de la abundancia de los asotes y abérsele podrido con la calor de estos parajes (ANB 59: 53r).

Junto con horrorizarnos, el castigo de María Micaela puede parecernos desproporcionado en comparación con los que recibieron Juana Antonia, Francisca Elvira o el mismo Diego Cruz Moro. Si considerarnos que en la época el castigo recae sobre el crimen, por lo que no es tanto el hecho de que sean brujos lo que se condenaba sino los delitos cometidos por arte de brujerías, a María Micaela debió habérsele acusado de cometer un crimen mayor que los confesados por los otros curanderos.

\section{El Corregidor maleficiado}

El temor de ser víctima de los maleficios de algún brujo o hechicero, comenzó a provocar las más

7 Recordemos también, que las declaraciones de Juana Estefanía son las tomadas en 1753, una vez que había regresado al pueblo después de su fuga en 1749, y los apremios recibidos y el propio interrogatorio bien pudieron ayudarla a construir otra escena de brujería. increíbles lecturas de los hechos cotidianos. Un pedazo de lana que impedía que la bombilla succionara el mate que tomaban en la tarde unas mujeres en casa del Corregidor, no hubiera pasado de ser un percance en las tareas diarias que Juana Estefanía cumplía como india mitane en la casa del Corregidor Manuel Fernández Valdivieso:

que abiendo bisto dichas mugeres lo que llego a ocupar dicha soga el hueco del mate sin poder rebolber la bombilla pasaron a reconocer y hallaron dicha soga con lo qual se alborotaron y hicieron llamar a dicho Correxidor quien haviendo visto lo acaesido mando prender a la metane (ANB 58: 11r)

La mitane fue detenida por su contacto con María Micaela, que en ese entonces se hallaba encerrada en la cárcel y a la cual ella llevaba los alimentos. Fue esta circunstancia la que había llevado a las alborotadas mujeres a pensar que el pedazo de lana era parte de un procedimiento de brujería. Debiéramos detenernos un momento para ver esta extraña paradoja de la acusación de brujerías en las que los acusadores parecen tener más claridad de los procedimientos ocupados en el maleficio que los propios acusados ${ }^{7}$. Marcos Zuleta, marido de AntoniaArasena una de las mujeres que se encontraba aquella tarde en la casa del corregidor, reconstruyó en su declaración cada uno de los pasos:

le conto dicha su mujer tenia la costumbre dicho Corregidor de tomar mate sobre tarde para lo qual avia dispuesto dicha Maria Micaela darle a dicha mitane en un tachito un poquito de agua prebiniendole que aquella la echase en el tacho de agua caliente que estava dispuesta para el correxidor y no habiendose reconoxido esa tarde dicho correxidor a su casa se ofrecio pedir el agua caliente en la ollita que servia de mate y a poco tiempo de haver tomado unos tragos del con bombilla remanesio dentro de dicho mate u ollita un pedazo de soga de lana retorcido que este con la misma umedad del agua y pasado el tiempo dispuesto por arte diabolica podía haverse yntrodusido en el cuerpo a no haver tomado dicho mate con bombilla porque dicho correxidor no solia usar bombilla (ANB 58: $11 \mathrm{r}$ ).

La declaración de Marcos Zuleta tiene la ventaja 
de demostrar la manera cómo en la época operaba un determinado tipo de maleficio: un objeto insignificante adquiría la capacidad de provocar un fuerte daño por la vinculación que había entre el causante y el demonio, es precisamente a éste al que es referido la eficacia del procedimiento. También aquí se introduce un elemento que puede explicarnos el maleficio del que había sido objeto Juana Pascuala: había un desarrollo natural de la enfermedad, que se podía rastrear por la aparición de los síntomas, pero cuando los síntomas se presentaban al observador de manera alterada, era otra la temporalidad que estaba funcionando: «pasado el tiempo dispuesto por arte diabólica».

Cuando Juana Estefanía fue interrogada por el Corregidor ajustó su declaración a lo formulado por Marcos Zuleta y que al parecer formaba parte de «lo público y notorio»:

teniendo presa el Correxidor actual a Maria Micaela yndia de Betere muges de Diego Cruz Moro por bruxa y corno dentraba a berla a darle la comida y el agua dise que una tarde le dio dicha Maria Micaela un tachito de barro que tenía a su lado con agua disiendole echa echase [sic] aquella agua en el tacho que estava dispuesto al fuego con agua caliente que se disponia para dicho correxidor como que todas las tardes tomaba mate y que esa dicha tarde acesio no benir a tiempo de haver benido doña Antonia la muger de don Marcos Zuleta a bisitar a una forastera que se hallaba en dicha casa con lo qual pidieron la agua caliente esta misma que se hallaba de mitane la llebo y echo con sus mano en la ollita que tenía dispuesta dicha señora para mate y en brebe ynstante bio que se asustaron dichas señoras y llamaron dicha declarante y le mostraron el pedazo de soga de lana dentro de dicha ollita que ocupaba todo el buque de ella a cuyo tiempo llego dicho Correxidor y le mostraron y le contaron lo que pasava con lo cual, apremio a esta declarante dandoles unos asotes y le declarase la verdad disiendole aberme dado dicha María Micaela el tachito (ANB 58: 12v).

Los azotes y el fantasma colectivo de la brujería fueron moldeando la declaración de Juana Estefanía. Esta afirmación podría corresponder a la óptica que hemos ido asumiendo con respecto al proceso por brujería que el Corregidor Fernández Valdivieso seguía a un grupo de curanderos atacameños. Sin embargo, nada impide pensar que efectivamente el Corregidor haya sido objeto de un daño por parte de María Micaela y que ésta haya utilizado a Juana Estefanía como medio para lograrlo. Esta visión se ajusta bien a aquella que ve en la brujería un mecanismo de rebelión y desestructuración del orden y la cultura dominantes (cf. al respecto Michelet 1987), una suerte de reacción contra los abusos que estaban sufriendo los curanderos, pudiendo extenderse la persecución hacia otros segmentos de la población indígena, sobre todo si consideramos que en sus márgenes deambulaban, con su complicidad, los brujos y hechiceros.

Fue en presencia de María Micaela que el Corregidor interrogó a Juana Estefanía con la ayuda del alcalde Miguel de Agüero, quien sirvió como intérprete. María Micaela negó haberle entregado a la india mitane la preparación del maleficio, inculpando a la abuela de la india de tal acto:

me dixo que seria mi abuela que esa mañana la habia visto entrar a la cosina y bisto la negasion que hacia la referida Maria hiso traer dicho señor a mi abuela y la apremio a lo qual respondio no ser ella que su nieta lo sabria» (ANB 58: 12v)

Luego de declarar Juana Estefanía logró fugarse permaneciendo oculta en la orilla del pueblo hasta que sus parientes o amigos lograron enviarla al pueblo de Toconao. Pasado un tiempo, volvió a San Pedro pero permaneció oculta por un año y medio a raíz del «miedo de lo precedido» (ANB 58: 13r), es decir de los castigos que ella y su abuela habían padecido como la muerte posterior de la inculpada en el fallido maleficio contra el Corregidor.

A la llegada de Juana Estefanía se sumaba la presencia de Juana Antonia y su madre, quienes habían vuelto cuatro meses después que se hubo ordenado su destierro en el año de 1749. El Corregidor ordenó en julio de 1753 que «se les notificase a Francisca Elbira y su hija Juana Antonia cumpliesen el destierro que por entonces les impuse» (ANB 58: 20r).

Con el testimonio de Juana Estefanía y el de los indios que en el año de 1749 habían ocupado los cargos de alcalde, más otros testigos que estuvieron involucrados en los hechos, el Corregidor Manuel Fernández Valdivieso dio por concluido un proceso que, por la gravedad del asunto, envió a la Real Audiencia en marzo de 17,54. 


\section{BRUJERIA, CONTROL POLITICO Y REPRESENTACIONES IDEOLOGICAS}

El proceso por brujería, llevado a cabo por el Corregidor de Atacama Manuel Fernández Valdivieso, suscitó una fuerte reacción por parte del fiscal protector de la Real Audiencia de La Plata. Reacción que, una primera lectura de la relación del fiscal protector, podría vincular al hecho que el corregidor no se ciñó al procedimiento jurídico establecido para

8 Ana Sánchez (1991) sugirió que los papeles del Santo Oficio referido a la hechicería permitían acceder, desde el siglo XVII, a tres niveles de actuación de comportamiento frente a la hechicería, los que era posible remitir a tres sistemas de referencia distintos: el de las altas esferas fiscales, los funcionarios medios y las víctimas y acusados. Las altas esferas requerían pruebas positivas y externas para los casos de brujería, y guardaban distancia de los estallidos de violencia colectiva que caracterizaban la persecución de brujas y de lo que los propios acusados decían de sí en sus declaraciones. Los maleficios y desgracias que sufrían las supuestas víctimas de brujería, debían tratar de explicarse a partir de causas naturales o divinas, como castigo a los pecados (1991: 34-35). Las concepciones racionalistas de las altas esferas fiscales contrastaba con las esferas de poder local. Sus representantes compartían el mismo imaginario que los sujetos que vigilaban y controlaban. «Seguros de la objetividad y validez de la máquina en que operaban admitían la existencia de los poderes ocultos, y se lanzaban contra ellos armados en los parámetros que ofrecía una tenebrosa mitología inquisitorial construida en los tratados de demonología y la praxis de la representación» (1991: 36). La brujería cobraba una mayor fuerza de realidad en los acusados y en las víctimas, pero ésta era una situacion que abarcaba a diferentes niveles sociales (Sánchez, 1991: 34-35, 36, 38).

9 Con las Instrucciones de Toledo en 1574, el poder se las había arreglado para extender su mirada a un Virreinato convulsionado por las guerras contra Vilcabarnba, la resistencia de los poderes locales hispanos y el resurgimiento inquietante de las «idolatrías». El juez de naturales o corregidor fue el dispositivo mediante el cual el poder se extendió hacia los pueblos y repartimientos de indios, también convulsionados por las vejaciones de los hacendados y las tiranías de los caciques. Veáse ANB -1764- Expedientes Coloniales No 131: 80-123. la toma de declaraciones a los indios y la dictación de sentencias. No obstante, es posible realizar cortes en los discursos del Corregidor y del Fiscal protector que permitan establecer el lugar que ocupa, en cada uno de sus imaginarios, la representación ideológica de la brujería ${ }^{8}$.

Hemos visto que el Corregidor, los acusadores y los testigos creían firmemente en la eficacia de los brujos, como para haberlos perseguido, interrogado y castigado. También nos hemos referido a las representaciones de la brujería que existían en la propia sociedad indígena. En este nivel, importa destacar el hecho que tanto las acusaciones derivadas de testigos hispanos como indígenas tuvieron la peculiar característica de reconocer a curanderos indígenas como los responsables de los maleficios. Evidentemente, la pregunta que surge es ¿por qué los acusadores y declarantes en el juicio por brujerías identificaron a los curanderos con estas prácticas y con el pacto con el demonio?

Primeramente, tendríamos que sostener que la identificación curandero-brujo forma parte de una sobredeterminación producida tempranamente por la dominación colonial, tanto en sus variantes políticas como eclesiásticas. Sobredeterminación que está vinculada con la delimitación de los márgenes del cuerpo social colonial y la identificación de aquellas prácticas que, localizadas en el mundo indígena, podían potencialmente provocarle daño: borracheras, idolatrías, supersticiones, vicios, etc. Es decir, todas aquellas prácticas y conductas que significaran una desviación con respecto a la policía cristiana y política, y que encontraron una primera racionalización en las Instrucciones de Toledo de 1574 .

Los dispositivos de control político, puestos en escena por las Instrucciones de Toledo, como es el caso del corregidor, tuvieron por propósito mirar, proveer y castigar, entre otras cosas, los vicios, idolatrías y supersticiones de sus antecesores; es decir, la mirada se dirigía hacia aquellos espacios en los que el daño podía poner en peligro el ordenamiento social. El daño tenía una doble dimensión, como daño individual y daño social, y era representado como un deterioro de la salud del alma y el cuerpo. A partir de su polifonía, la expresión «daño» podía ser considerada en relación con la expresión «mal», en la medida que ésta denota el «daño moral material», y de este modo ser remitida al «mal» como «lo contrario al bien» (Casares 1994: 528). De este modo, la teoría del daño indígena podía ser interpretada, como lo hemos señalado anteriormen- 
te, a la luz de las representaciones demonológicas europeas. Las Instrucciones de Toledo no sólo circunscribieron y reconocieron un conjunto de positividades que reclamaban la intervención del poder, identificaron también a los agentes reproductores del daño:

Ordeno, e mando que de cada cosa de estas tengais expecial cuydado de saver, y entender quien los hase, e comete adbertireis que es negocio substancial en mirar por los viejos domaticadores, y hechizeros ya referidos que son el instrumento e cauza de todo el mal, e avizarleseis en sus congregaciones públicas, para que se abstengan, e aparten de todo ello, sertificando que se castigara con gran rigor como sea en pecado a hazer (Instrucciones..., -1774- ANB 131: $87 \mathrm{v}-87 \mathrm{r}$. Subrayado nuestro).

Localizado como «el instrumento e cauza de todo el mal», la figura del hechicero fue inscrita, de este modo, entre los chivos expiatorios coloniales. Quizás sea el hecho de su vinculación con las prácticas rituales de la comunidad, que fueron consideradas como expresión de la idolatría y de la acción del demonio, el que explica que su acción fuera tan

10 La ambigüedad que adquiere la figura del curandero indígena, no es un proceso exclusivo de América. Durante los siglos XIII y XV, en Europa la vetula fue objeto de un proceso cte representación, que tuvo en el orden médico y en el religioso, a sus principales impulsores. Representada en un primer momento, por la iglesia, como mujer piadosa y beata, se le reconoció también cierta localización en la jerarquía más baja de la medicina empírica. Esta percepción difusa y ambivalente que se tenía de la vetula, de sus privilegios y poderes, es homogeneizada en una concepción enteramente negativa: «sus 'competencias', sus poderes y sus actos no le son más atribuidos directamente a ella o a sus pares, sino al demonio, del que ellos son instrumentos. Una desviación amenazante pero marginal, difusa, desparramada ha sido pues 'construida', como un enemigo único, más fácil, sin duda, de señalar, de identificar y de destruir» (Agrimi y Crisciani 1993: 1307).

11 Respecto a la permanencia de este fenómeno en comunidades indígenas contemporáneas, vcáse Yauri (1994: 232-233). peligrosa para la mantención del cuerpo social. Ligado a la reproducción de las prácticas idolátricas, el hechicero representaba el mayor daño para el cuerpo social, sobre todo para la salud del alma, al llevar a los individuos al pecado. La relativa facilidad con la que actuaban los hechiceros se debía, entre otras cosas, al apoyo que les daban los caciques, el secreto con el que realizaban sus prácticas, el temor que los indios le tenían, etc. Además, contaban con una estructura que permitía la transmisión del oficio de ministros de la idolatría: por sucesión de padre a hijo, o al pariente más cercano; por la elección que hacían los caciques y curacas de algún individuo que tuviera alguna característica especial, por ejemplo el herido por el rayo; o simplemente por elección personal, especialmente entre «los viejos y viejas, que por ganar de comer, [...], se hacen oficiales en estos ministerios» (Arriaga 1968 [16211]: 207). Esta verdadera estructura de ministros de la idolatría, que describen los tratados misioneros, permite la reproducción de la idolatría, el menoscabo de la salud del alma y del cuerpo, el desorden social, etc., porque «en todas ocasiones y a todos tiempos les están repitiendo las cosas que aprendieron con la leche y que son conforme a su capacidad e inclinación» (Arriaga 1968 [1621]: 221).

Si bien la acción de los curanderos había sido localizada en el conjunto de prácticas que ponían en peligro el cuerpo social, ellos ocupaban un lugar ambiguo por el conocimiento del tratamiento de las enfermedades que afectaban a los indígenas:

Muchos de los hechiceros son anbicamayos, como ellos llaman, o curanderos, nderos, pero con muchas supersticiones e idolatrías, que preceden a las curas, y se procura que los curas tengan examinados y bien instruidos a los que han de curar para que, quitando lo que es supersticioso y malo, se aprovechen de lo que es bueno, como es el conocimiento y uso de algunas yerbas y de otros simples de que suelen usar en sus enfermedades (Arriaga 1968 [1621]: 238)10.

No obstante, la hegemonía colonial relegó al curandero al espectro de los mi nist.ros de la idolatría, imponiendo en el imaginario indígena una ligazón hasta entonces inexistente entre aquél y el demonio $^{11}$. Algunos autores han sostenido que «el acento de la hechicería es una necesidad del lenguaje, la justificación de la extirpación en nombre del combate contra el diablo» (Bernand y Gruzinski 1992: 167 
y ss.). En la identificación del curandero con las prácticas de brujerías, podemos establecer el poder de una representación ideológica que se extendió, al menos entre su población y sus autoridades locales, en la región de Atacama hasta el siglo XVIII ${ }^{12}$. Sobre todo, si consideramos que hacia 1749 esta representación fue manipulada para lograr un control más efectivo sobre los indígenas:

12 Gareis ha estudiado los procesos contra idólatras y brujos, desarrollados durante el siglo XVIII en el Obispado de Trujillo, destacando el hecho que los acusados de ser brujos eran en realidad curanderos cuyos procedimientos «eran calificados de supersticiosos por los jueces, los cuales tenían por cierto que solo mediante la intervención del diablo era posible llevar a cabo las adivinaciones y curaciones» (1994: 215). Esta situación explicaba el hecho que los curas, que tenían a cargo el proceso, sostuvieran que tales facultades sólo podían ser obtenidas mediante un pacto con el demonio. Además, para una discusión actualizada de la bibliografía europea sobre las brujerías y el pacto con el demonio, veáse el estudio introductorio de Campagne (1997).

13 Sobre el lugar que ha ocupado el demonio en las representaciones judeocristianas sobre Dios, el hombre y el universo, puede consultarse el libro de Langton (1951). Para un estudio erudito sobre el Diablo en la tradición hispana puede consultarse Flores (1985).

Durante los siglos XV y XVI fue objeto de una amplia discusión la forma en que se transmitía la acción demoníaca y la manera cómo dicha acción se ocultaba bajo la apariencia de prácticas disímiles. El demonio no tenía la facultad de intervenir directamente sobre el inundo, ni siquiera de alterar la naturaleza, pero su acción fue localizada en la mediación entre el hombre y el mundo, en una facultad del alma denominada imaginación. En la imaginación la naturaleza se transforma en imagen, por un proceso que va del cuerpo al alma y del alma al cuerpo, permitiendo de esta manera no una alteración de las cosas sino una confusión en sus apariencias en las que se localiza la acción demoníaca. El diablo logra esta confusión en espíritus débiles, sacando provecho de las debilidades y de los defectos, al punto de pasar de un orden del mundo, en el que él está sometido, a los desórdenes del alma que él logra someter (Foucault 1990: 16-21; también Flores 1985: 34-57). para la enmienda y suxesión que deben tener los Yndios de esta Provinsia por la libertad en que viven y ydolatrías que permanesen en ellos con las supersticiones que el demonio les hase creer (ANB -1754- 58: 2r).

El Corregidor está argumentando que las prácticas de brujerías no tan sólo son eficaces, sino que siguen practicándolas los indios «por la libertad en que viven», es decir, que la carencia de sujeción, o si se prefiere, de dispositivos de control eficaces que dirigieran su mirada, proveyeran y castigaran las idolatrías y las supersticiones, permitían también la reproducción de estas prácticas idolátricas. El idólatra forma parte de los desviados, «de los fantasmas y las obsesiones que atormentan al dominio de lo imaginario en las sociedades ibéricas, al lado de los judíos, los sodomitas y las hechiceras» (Bernand y Gruzinski 1992: 145). El Corregidor introduce un segundo elemento, la acción que el demonio ejerce sobre los indígenas ${ }^{13}$. El manual de Arriaga sobre extirpación de idolatrías había insistido que «el demonio estorba y divierte por muchas vías», al extremo de someter a los indios a una verdadera ceguera (Arriaga 1968: 236, 242). Afirmación cuyo referente está dado por las Instrucciones de Toledo de 1574:

es cosa ordinaria inclinarse esta jente a los vicios, e ydolatrias, e supresticiones de sus antesezores, mayormente quando son flacos, y nuebamente conbertidos, como estos naturales tienen menos resistencia a las tentaciones, y buelbense a los sacrificios, y seremonias antiguas de la jentilidad hasiéndolas públicamente de que resulta gran daño e perjuicio para su conuerción mayormente teniendo como tienen consigo los viejos domaticadores hechisseros que es eficasissimno estorbo de ella (ANB -1764- 131: 84r-84v).

El que los indios «son flacos»y su «menos resistencia a las tentaciones», junto con connotar un defecto moral entre los indios, en el sentido que la serie de aficiones se habían ido creando por su inclinación ordinaria «a los vicios, e idolatrías, e supresticiones», es antes que nada una representación ideológica que circunscribe un espacio de intervención del poder constituido por los propios cuerpos y almas indígenas amenazados por prácticas 
idolátricas a las que es necesario detener ${ }^{14}$. Esta «menos resistencia a las tentaciones» daba por presupuesto que los indígenas quedaban más expuestos a la acción del demonio, como lo sostuvo el Corregidor Fernández Valdivieso.

El maleficio practicado contra una española, así como contra los dispositivos de control político hispanos e indígenas, era el hecho más positivo de la permanencia de las supersticiones e idolatrías $\mathrm{y}$, sobre todo, de la acción del demonio sobre los indígenas. De ahí que los maleficios representaran delitos y desviaciones del esquema de dominación colonial en la medida que suponían un pacto con el demonio (rechazo implícito de la policía cristiana) utilizado para dirigir ataques tanto a los miembros hispanos e indígenas de la sociedad colonial como a los dispositivos de control políticos: el Corregidor, los alcaldes y gobernadores indígenas ${ }^{15}$. Y fue precisamente esta desviación la que legitimó la racionalidad de las tácticas punitivas que el Corregidor utilizó para controlar a los «muchos abitadores de esta provincia así hombre como mugeres bisiados en este

14 Bernand y Gruzinski han llamado la atención sobre las distintas perspectivas que asumieron los extirpadores en México y Perú en relación al indio idólatra: en el primer caso se acentuaba la responsabilidad de los indígenas en las prácticas idolátricas, al punto de equipararlos con heréticos perniciosos; en el segundo caso, el indio idólatra es más bien un juguete del demonio, seres pasivos incapaces de rechazar su influencia por sus propios medios (1992: 170).

15 El poder colonial representó el orden social como divinamente inspirado, ligado vertical y horizontalmente, de modo que cualquier cambio traía consigo un cambio en todos los órdenes. «De ahí que aun cuando se tratara de un orden en movimiento, en esencia nada debía alterarlo puesto que hacerlo era ir contra Dios... Intentar cambiarlo implicaba instaurar el desorden, el desgobierno, la tiranía $\mathrm{y}$, como si fuera poco, ponerse al margen de la humanidad». De esta representación se derivaban dos cuestiones: 1) que el orden establecido era la imagen del reino celestial y, 2) se podía invertir colocando un orden simétricamente opuesto, la tiranía del demonio. Denunciar, perseguir y castigar a quienes practicaban el pacto con el demonio «era un acto eminentemente político» (Flores, 1991: 64).

16 Cf. supra nota 7. exersisios pues se atrebieron a executar lo mismo conmigo» (ANB -1754- 58: 21r).

Otra historia cruzaba el imaginario del Fiscal Protector y de los miembros de la Real Audiencia de la Plata ${ }^{16}$ que conocieron el expediente enviado tardíamente por el Corregidor en marzo de 1754.

El Fiscal Protector calificó el expediente como una «desgreñada serie», en cuyas:

actuaciones, diligencias, y resoluciones tomadas, se enquentra, no solo una total incuria, y modo de proseder opuesto a Derecho, sino también una clara, y manifiesta injusticia, y así mismo la total indefensión con que los miserables, que son sindicados de reos han sido tiránicamente sugetos, comprimidos a la hostilidad, y castigos, que consta del proseso haber en ellos exequtado este corregidor, siendo su contexto un claro conbensimiento de sus iniquidades (ANB 1754- 58: 21v).

Cada uno de los procedimientos utilizados por el Corregidor, fueron evaluados a partir de las normativas del derecho: en primer lugar nombró como único intérprete al indígena Francisco Ziari, quien también actuó en el proceso contra Diego Cruz Moro como intérprete, acusador y ejecutor de sentencia, lo que anulaba las declaraciones hechas por los acusados. A lo que agregaba el uso de azotes con los que se arrancaron las declaraciones y el hecho que el Corregidor ya hubiera dictado sentencia en casos que estaba solicitando un pronunciamiento de la Real Audiencia.

Del informe del Fiscal nos interesa destacar la mirada que él tuvo de la brujería, y que lo distancia notoriamente del Corregidor, de los acusadores y de los propios acusados. Para el fiscal, dos son los hechos reales contenidos en los autos remitidos por el Corregidor: el accidente que aquejó a la enferma y los castigos y hostilidades a que estuvieron sujetos los indígenas durante el proceso, y que no era más que el contexto de «un claro conbensimiento de sus iniquidades». El Corregidor fue poco diligente en la acumulación de hechos positivos que confirmaran la presencia de un maleficio y el uso de prácticas de brujería:

en que entre otras cosas de bilis y risibles depusieron que preguntándoles por el accidente que la oprimía a la enferma, les respondía ésta, haber visto entre sueños 
una india Juana Antonia de aquel pueblo hija de Francisca Elbira y que le introduxo un atado de cabellos por la boca, y no pudo defenderse, y así mismo asientan, que uno de estos dos testigos Domingo Valdibieso le hiso arrogar por la boca a la pasiente un atado de cabellos muy bien amarrados con el bomitorio de un poco de agua tibia (fácil medicamento por cierto para quitar la eficas fuerza de un imaginado hechiso) y sin más mérito que este soñado fundamento, pasó el Corregidor a dar una providencia nada despierta (ANB -1754-58: 22r).

Es evidente que en su informe el Fiscal ha realizado un desplazamiento de significado, conservando el referente de la mujer accidentada, situándola como enferma y paciente, cuestión que anticipa la perspectiva del Fiscal sobre los hechos. Los fundamentos de la acusación le parecen débiles, pues se basan en la opinión de la enferma que vio entre sueños a Juana Antonia y una confirmación del maleficio realizado por un procedimiento al que le resta cualquier eficacia, y si le reconoce alguna eficacia lo hace por la relación entre una imaginaria manipulación y un no menos «imaginado hechiso». La ausencia de hechos positivos tendientes a confirmar las acusaciones de brujería, fue denunciada también por el Fiscal en referencia al proceso de Diego Cruz Moro quien había confesado una «multiplisidad de delitos y muertes practicadas con hechizos, ya en racionales, ya em brutos, sin más comprobasión, cuerpo de delito, ni otro fundamento alguno, que el de la nuda asersión de la declaración tomada mediante la reprovada interpretación del mismo denunciante» (ANB -1754- 58: 23r).

La distancia entre el Fiscal protector y el Corregidor se estableció también con respecto a la representación que cada uno tenía del indio, y que legitimaban el modo de ejercer, sobre éste, el control. Para el Corregidor eran sujetos viciados por la acción del demonio, por su parte el fiscal sostuvo que eran «de el todo inocentes, sin mas delito que haber nasido con el influxo de desdichados, y como tales dispuestos hacer unico pabulo y obxeto, que debora la malisia, particularmente la notoria de sus Corregidores» (ANB -1754- 58: 23v). El Corregidor había fundamentado sus tácticas punitivas y el rigor de la sujeción de los indios, en el hecho que la libertad en la que ellos vivían significaba, implícitamente, la libertad de la acción del demonio, que era evidente en las supersticiones e idolatrías que practicaban. Sin embargo, el
Fiscal provoca un deslizamiento que invalida la argumentación del Corregidor, cuestionando la legitimación del modo en que ejerció el control político sobre los indios. El Fiscal libera a los indios de cualquier responsabilidad: miserables, infelices, inocentes son expresiones que utiliza para reafirmar el hecho de que el único delito de los indios sería el de «haber nasido con el influxo de desdichados», y esta situación los convierte en «pábulo y obxeto» de los abusos del poder local. Dicho de otra manera, el enunciado indio supersticioso e idólatra, construido por el Corregidor para legitimar su actuación entre los indígenas, es desplazado por el de indio miserable, infeliz e inocente, tendiente a demostrar el «claro conbensimiento de su iniquidades», expresión que articula el discurso del fiscal.

En el proceso se impuso la opinión manifestaba por el Fiscal protector. La Audiencia de la Plata declaró nulos los autos realizados por el Corregidor Fernández Valdivieso, restableciendo los mecanismos coloniales de justicia que por un buen tiempo éste había ignorado. Pero también se restableció el control de la burocracia central sobre un poder local que actuaba arbitrariamente:

Se le apersiva que en las causas de esta naturaleza y en las demas que actuare pertenenciente a yndios las sustancias conforme a derecho, examinando los testigos que fueren yndios, con dos ynterpretes juramentados, y nombrandoles a los yndios una [vez] que fueren reos, protector que los defienda, sino lo hubiere en la provincia nombrado, que con audiencia de este, sustancie la causa, oyendoles sus defensas, sin determinarlas por si solo ni por su arbitrio siendo la causa grave, sino con asesor, a quien debe remitir con zitacion de las partes y siendo las sentencias grave como de muerte, destierro perpetuo, o Casa de Moneda, no pase a ejecutarla, sin dar primero quenta a esta Real Audiencia con los autos (ANB -1754- 58: 26r).

Queda por plantear un último problema relacionado con la denuncia del Corregidor sobre las prácticas de brujería y el pacto con el demonio. ¿Qué significa el desplazamiento que estableció el Fiscal en su Relación de los autos remitidos por el Corregidor, al punto de restar importancia a las supersticiones e idolatrías ahí denunciadas y de deslizar las acusaciones hacia el Corregidor? En el discurso del corregidor el enunciado 'indios supersticiosos idóla- 
tras' tiene un rasgo performativo pues crea su propio referente, con la intención de apelar a la Audiencia obligándola a realizar una determinada lectura de los autos que justificara los procedimientos que había utilizado para la averiguación de los delitos de brujería. Habiendo intentado entregar, con los autos del proceso, un «corpus positivo» que diera solidez a sus argumentos, el Corregidor no encontró eco a sus acusaciones entre quienes pedían más que enunciados retóricos, comprobaciones obtenidas mediante procedimientos positivos y ajustados a derecho. En buenas cuentas, el Fiscal no estaba cuestionando el que los indios pudieran estar viciados por las supersticiones o de practicar algún tipo de idolatrías ni menos aún negar la facultad del demonio para actuar sobre éstos, cuestiones que en su Relación son excluidas o silenciadas. Si la Relación exime a los indios de cualquier responsabilidad en los delitos de brujería, no lo hace negándole existencia a tales prácticas, sino que, de practicarse entre los indios, éstas deben ser remitidas al hecho que ellos han nacido «baxo el influjo de desdichados», expuestos a la malicia tanto del corregidor como la del demonio, esta última se encuentra silenciada en la Relación del Fiscal.

La acción del demonio era posible entre sujetos miserables e infelices, cuya desdicha aumentaba con el desconocimiento de la doctrina cristiana. Esta ignorancia de la dogmática cristiana bien podía ser el fermento de las supersticiones y de las prácticas idolátricas. La Real Audiencia previno:

al Corregidor que a dichos yndios los ponga en casa de alguna yndia de virtud para que se instruya en las christianas obligaciones dando presente al cura, para que en cumplimiento de su obligación concurra a tan justo fin (ANB -1754- 58: 26r).

Con esta última sentencia, se pone de manifiesto el carácter periférico de las prácticas de brujería con respecto a los núcleos de cristianización. Como bien lo ha señalado Chaunu: «La brujería constituye bien el mundo disperso de todas las periferias. Los brujos están en los bosques, viven en el arenal, en las montañas, en los pantanos, en la selva. Están implantados en la periferia del mundo agrícola» (Chaunu 1969: 903). Para la Real Audiencia, los márgenes en los que se localizaban las prácticas de brujería demostraban antes que nada la ausencia o el fracaso de la labor de evangelización. Al parecer los curanderos atacameños, eran sujetos que se encon- traban fuera del área de influencia, no tan sólo de los dispositivos políticos sino que también de los de carácter religioso.

Es de resaltar que, durante el proceso, y dado que se trataba de situaciones que competían directamente al cuidado de las almas, no hubo participación directa de los curas de la Provincia, salvo la referencia hecha por Domingo Valdivieso de que un cura suplente vio el «atado de cabellos» que extrajo del cuerpo de la maleficiada Juana Pasquala. Aunque el mismo Corregidor tuvo la intención de enviar la información al comisario del Tribunal de la Inquisición, no hay prueba alguna de que las haya enviado. Por lo demás, la Inquisición no tuvo nunca jurisdicción sobre los indios (Millar 1996: 42). Esto podría llevarnos a pensar la existencia de alguna pugna entre el Corregidor y las autoridades religiosas de San Pedro, a las que aparto intencionalmente del proceso como un modo de criticar el descuido de sus tareas de adoctrinamiento. Pero, como veremos más adelante, en muchas ocasiones aquél actuó con la complicidad de las autoridades religiosas.

La ausencia de religiosos durante el proceso, se justifica en el hecho de que, para el Corregidor, la presencia de indios idólatras en manifiesto trato con el Demonio era una cuestión «de mi obligasion por hallarme con el cargo de Correxidor» (ANB -175458: 2r). Recordemos también que la lucha contra el Demonio era antes que nada una medida política, por cuanto se defendía un orden social divinamente inspirado.

\section{LA RESIGNIFICACION DE LA BRUJERIA EN ATACAMA, 1755}

A fines del mes de mayo de 1755, la Real Audiencia de La Plata había dictado sentencia en relación a los autos presentados por el Corregidor de la provincia de Atacama. Dos meses más tarde, la Real Audiencia ordenó someter a sumario al Corregidor Fernández Valdivieso para averiguar la pertinencia de las denuncias hechas en su contra por algunos indígenas atacameños. Una de las preguntas del interrogatorio trataba de indagar sobre:

si el referido Corregidor se propasó a mandar a asolar a Maria Micaela muger de Diego Crus Moro, (por abérsele imputado ser bruga) con rigor tan inhumano, que le hicieron una llaga, por donde se le salieron las tripas, de que probino siertamente la muerte de esta infelis (ANB -1755- 59: 1v) 
Aunque la Relación del Fiscal había vinculado la muerte de María Micaela «sin duda a impulsos de sus experimentados padesimiento» (ANB -1754- 58: 24r), no le dedicó a este caso demasiada atención como para responsabilizar directamente al Corregidor de su muerte. Sin embargo, esta afirmación del Fiscal permitió, a los indígenas que acusaron en 1755 al Corregidor, resignificar los hechos referidos al proceso de brujería para evidenciar la tiranía a la que estaban expuestos en todo orden de cosas. Además, contaban con el hecho que las pruebas presentadas por el Corregidor habían sido insuficientes para comprobar los delitos de brujería. De este modo, manejando y manipulando la Relación del Fiscal, los indígenas pudieron entregar una versión naturalizada de los hechos en la forma de lo que es «cierto que es notorio y público a todos los de este pueblo» (ANB -1755- 59: 35 r). Por lo que la información que entregaron los indígenas para la formulación del interrogatorio del sumario, enfatizó el hecho que a María Micaela se le había «imputado ser bruga». Pero también parte de los testigos resignificaron el accidente por el que Diego Cruz Moro y su mujer habían sido acusados de brujo.

Es importante retener la declaración de Fernando de Araya, que en la época del proceso había aprehendido a Diego Cruz Moro y presenciado su interrogatorio:

17 Lo que vincula al Corregidor con el nacimiento de Lorenzo, hijo de Juana, es la coincidencia de nombres con uno de los testigos en los autos de 1749, don Zenón Zuleta, a quien también el Corregidor había entregado a Juana Antonia para ser desterrada a la estancia de El Paposo que aquél poseía en la jurisdicción de Santiago de Chile. Otro caso que relaciona al Corregidor Manuel Fernández con el nacimiento de una niña de padre, y en este caso, y madre desconocidos se encuentra en el mismo libro de bautismo: «... Yo el Rdo. Padre, Fr. Basilio Zánchez de Rueda... baptisé... a Juana Gerbasia española criatura de quatro días, espuesta que fue a las puertas del gral. Dn. Manuel Fernández de Valdivieso y Arbizú Corregidor y Justicia Maior... fue su padrino de agua y el óleo el referido, dn. Juan Antonio de Mier y Terán...» (Libro... -1737 1784- f. 138). Es del todo extraño que de una criatura dejada en la puerta de la casa del Corregidor se supiera que tenía tan sólo cuatro días de nacida y que en su bautizo participara como padrino don Juan Antonio Terán, un amigo personal del Corregidor además de ser el cura principal de Atacama en esa fecha. declara por testigo de bista por ynbiado del Corregidor como Alcalde fue a traer a Diego Cruz Moro marido de la dicha María Micaila y le dijo el Corregidor que fuese a curar a una mestisa llamada Juana que estaba hechisada y abiendo ido de miedo, y llegado a la casa de la referida Juana, no supo como curarla porque no entendia el hechiso mas reconoció que la dicha Juana estaba preñada de que se hallaba embarasada y dicho Corregidor por razón de que no atinaba a curarla, por cuya razón lo aprendio hasiendole cargo proponiendo de que era brujo (ANB -175559: $53 \mathrm{r}-53 \mathrm{v}$. Vedse también fs. $26 \mathrm{v}$ y $44 \mathrm{r}$ )

En los autos de 1753 realizados por el Corregidor Fernández Valdivieso, Fernando de Araya no hizo mención alguna a estos hechos. En esos autos, él declaró su participación en la detención de Diego Cruz Moro y de María Micaela, en la de otras dos mujeres sindicadas como brujas y en la persecución de la prófuga mitane María Estefanía (ANB -175458: 14v). Es plausible suponer también que las exclusiones que existen en las declaraciones de Fernando de Araya estén condicionadas por la dependencia que su autoridad, así como la del cabildo indígena y la del resto de los dispositivos indígenas de control político, tenían con respecto al Corregidor Fernández Valdivieso, y que las declaraciones que realizó en 1755 tengan más bien relación con un proceso de tensiones entre quienes ocupaban ciertos cargos de autoridad y el Corregidor. Sobre este punto volveremos más adelante.

La resignificación del accidente que sufrió Juana Pasquala en 1749, contaba con un hecho incuestionable:

En San Pedro de Atacama en diez de agosto de mill setesientos y cincuenta años Fray Lorenzo Cavallero de el orden de Predicadores Cura Coadjutor Vicario y Juez Eclesiástico de este Beneficio bautize puse oleo y chrisma a Lorenzo recien nacido hijo de Juana soltera española de este pueblo y padre no conocido testigo don Zenon Zuleta y Agustin Esteban padrinos Don Thomas Agüero y doña Juana Chavez a quienes hize saber obligacion y parentesco y para que conste lo firme (Libro de Bautismo de San Pedro de Atacama 1737-1784- f. 114).

El niño de Juana, la española maleficiada de los autos del Corregidor, debió nacer en abril o mayo de 
1750, de modo que sería un 'recién nacido' de tres meses a la fecha del bautismo ${ }^{17}$. Este hecho bien puede resignificar el contexto de la «enfermedad» de Juana Pascuala y la intervención de la curandera de Condeduque Juana Antonia, si ella practicó una terapia abortiva es una cuestión que no podemos dilucidar. No obstante, la incuestionable intervención del Corregidor levanta más de una sospecha. La pregunta que surge es que si el Corregidor estaba enterado del embarazo de Juana Pascuala ¿no fue el proceso mismo una parafernalia destinada a distraer la atención, en una situación en la que él podía estar comprometido sentimentalmente? Esto parece improbable, pues el proceso mismo obligó a centrar la mirada en una irrelevante muchacha, que, por lo demás, permanecía encerrada en la casa materna.

Si hubo la pretensión de manipular la acusación de brujería para ocultar el embarazo de una joven española, esto no le resta el peso real que aquélla tuvo durante el proceso de 1749. Hemos podido demostrar cómo se fueron dibujando, diseñando y cobrando realidad las representaciones coloniales del brujo, la brujería y el pacto con el demonio ${ }^{18}$. Lo que nos interesaba destacar, parafraseando a Laënec, es que, real o imaginaria, la brujería sirvió de pretexto para un control más riguroso de la población indígena y para una apropiación descarnada de los cuerpos y de los recursos indígenas.

El control que ejercía el Corregidor sobre los cuerpos nativos era evidente en las tácticas punitivas que sobre ellos aplicaba y en la disposición de los mismos dentro de un sistema de producción que iba a su entero beneficio. Disponiendo de sus cuerpos, el

18 Lo que «de hecho se descubre en acción [es] la fuerza de lo imaginario jamás denotado, y siempre puesto a inventar las combinaciones más asombrosas por saltos de una imagen a otra, en la repetición indefinida del 'mismo'» (Laënec 1993: 16).

19 Para el problema del reparto como parte de un sistema de expoliación así como el papel económico desempeñado por los corregidores puede consultarse Golte (1980), Tord ( 1974) y Moreno (1977). Para el área de Atacama hemos retomado algunas de estas problemáticas en algunos de nuestros trabajos (Hidalgo 1982, 1987).

20 Para una síntesis etnográfica de Atacama veáse Castro y Martínez (1996).
Corregidor también podía ejercer un control y una apropiación de sus medios de producción, sus materias primas y de sus productos.

\section{Repartos y monopolio comercial}

De acuerdo a las acusaciones hechas contra el corregidor Manuel Fernández de Valdivieso por los atacameños, las respuestas de los testigos y las propias conclusiones del protector general, éste intentaba practicar en Atacama un riguroso monopolio comercial de la oferta y la demanda de algunos productos agro-ganaderos y de caza ${ }^{19}$. Es poco probable que tal situación pudiese ser llevada a la práctica si tenemos presente los patrones de poblamiento de los atacameños, su movilidad por razones culturales y económicas (mercados laborales, ganadería, arriería, minería, transhumancia, comercio, etc.) entre varias provincias (Cf. Hidalgo 1978, 1984 ${ }^{\mathrm{TM}}$, 1984b, 1987; Hidalgo y Manríquez 1992; Martínez 1990; Núñez y Dillehay 1995) 20. Sin embargo, fue percibida como limitante de los derechos indígenas sancionados, tanto por las propias autoridades coloniales como por los miembros de la comunidad indígena, y que daban cuerpo a la economía moral comunitaria. Es decir, que aquí importa destacar no tanto los esquemas de dominación coloniales como el proceso de hegemonía cultural, que permitió a los indígenas situarse como sujetos protagónicos y como agentes activos frente a lo que consideraban como un menoscabo de sus justos derechos:

«2 Y ten si es cierto que dicho Corregidor es tan tirano con los yndios de la Provincia, que quitandoles sus conbeniencias, y lo presiso que tienen para su manutencion, les quarta, la libertad que deben tener en sus comercios, obligandolos a que en el que tienen, de lana de vicuña haian depracticar las bentas presisamente a dicho corregidor, en los precios baxos y infimos en que se les abona, de modo que no se les permite a los miserables yndios el que saquen ni baian a bender a otra parte dicha lana y cueros, aunque puedan lograr maior aprecio, por quitarselos el Corregidor.

3 Y ten si saben, an oido desir y les consta que dicho corregidor con la autoridad del jues les paga a los yndios por cada res, a baca a dos pesos, y ocho segun su intrinseco balor; y si asi mismo les satisface solo a quatro reales 
por cada carnero de Castilla, baliendo en la Cordillera donde los ay ocho reales $=$ Expresando ygualmente si en ello interbiene alguna biolencia, o fuerza.

6 Yten si es cierto que el Corregidor con el fin de sacar del sudor de los yndios sus logros, y adquirir caudal, les reparte contra la voluntad de estos ynfelises barios efectos, como son mulas, coca, ropa de la tierra, paño de quito $=$ Digan y expresen los precios determinados de cada cosa, declarando con distinción todo lo que en el asumpto supieren» (ANB -175558: 1r-lv)

Por las acusaciones que los indígenas dirigen al Corregidor, se podría concluir fácilmente, que estamos en presencia de una comunidad desintegrada por la explotación material a la que éste los sometía. No obstante, el recurso a la Real Audiencia expresa un nivel de resistencia fundamentado en una moralidad lo suficientemente estructurada como para discernir cuándo el orden justo estaba siendo menoscabado. Es ante todo la tiranía y el despotismo con los que actuaba el corregidor, expresados de manera material en la apropiación y el control desmedidos de los bienes y cuerpos indígenas, lo que se cuestiona.

El Fiscal Protector General estimó que las respuestas de los testigos - a pesar de lo atemorizados que se encontraban por las presiones del corregidor y del cura de Chiu Chiu, como veremos más adelanteconfirmaban los abusos del Corregidor (ANB -175559: $6 r, 8 r)$.

Juan Rodrigo, responde a la pregunta dos sosteniendo que en efecto «sabe que dicho Corregidor a sido mui tirano con todos, castigandoles rigurosamente sin mas motivo... el menor chismo...», señal que les quita la libertad a los indios:

Notificandoles que no pueden bender fuera de la provincia las lanas y cueros de vicuñas que les obliga por fuerza que se las vendan a el, y que llevandole la dicha lana y cuero, se los paga el dicho corregidor por el ínfimo precio de dos reales, costandoles a ellos tres reales, y quatro reales y que en la jurisdiccion de Salta les pagan a plata a cinco reales, y en generos a seis reales (ANB -1755- 59: 24r. Veáse además fs. 32v, 33r, 42r, 51r, 59r, 59v).

Para la pregunta tres citaremos la respuesta de uno de los integrantes del cabildo indígena, el alguacil Melchor Mamani que como tal sirvió de instru- mento a la voluntad del Corregidor. Afirma en la parte pertinente:

Con la autoridad de jues no les paga su justo presio a los miserables yndios como que le consta de hallarse este declarante de alguasil y dise que lo suele ynbiar el corregidor a las estancias para que traiga bacas y cameros de Castilla y abiendo traído contra la balun [sic] de sus dueños y quando bienen a resibir su plata sus dueños y con mucha oreja [sic] les paga a quatro reales baliendo en la cordillera un peso donde los cojen y las bacas a seis pesos siete y ocho conforme a los años que tienen asi mesmo dise este declarante abiendole pedido de su trabajo de aber ydo molestandose no le paga sinos todo rigor con amenasas de asotes asi mesmo dise que Antonio Martínez lo aniquilo quitandole once bacas y beinte carneros de Castilla diciendo que le restaba de resagos de tasas y le abono a menos presio y por los carneros de Castilla a quatro reales y en estos excesos bio (ANB -1755- 59: 59v-60r)

De modo que, de acuerdo a este testimonio, valioso por tratarse de un alguacil y que aparece refrendado por otras declaraciones, el Corregidor adquiriría a precios inferiores animales vacunos y ovejunos, utilizando su autoridad e incluso aprovechaba los resagos de la tasa para pagarse en animales que tasaba a precios ruinosos para los ganaderos atacameños.

Para la respuesta relativa a los repartimientos hemos elegido la de Fernando de Araya, quien responde del siguiente modo:

Dixo que es cierto y bio por rason de hallarse en la ocasion el alcalde este declarante que dicho corregidor por adquirir caudal como ambisiosos reparte a los miserables yndios contra su boluntad, forsadamente lo primero habiendo una nómina antes donde para lo que cada uno a de sacar de estos efectos y que de esta suerte los reparte, las mulas a beinte y sinco pesos. La coca a diesiseis pesos un sesto $=\mathrm{Y}$ por libras a dose reales de abios y a plata de contado a dies reales esto fue a los principios y despues a dos pesos libras y luego, la ropa de la tierra a dies reales y a dose el paño de quito a ocho y nuebe pesos la bara con la que bio dar. La lana de color reparte y de mala 
calidad podrida que apenas tendría cuatro onsas forsadamente les da a seis reales cada maitito, y así mesmo reparte a las mugeres la lana de color casadas y biudas y solteras coca y ropa de la tierra al mismo presio que a los demás, y que a esta cuenta por su conveniencia propia las molestaba a hilar y tejer ponchos los que ynbiaba a Potosi y Salta y a otras partes a bender para tener su logro asi mesmo tocante lana de color manda hilar con las yndias solteras dandoles pesada y faltando al peso por no enterar segun y como an resibido no les paga (ANB -1755- 59: 52v-53r).

Los repartimientos incluían mulas, cestos de coca (comentando el precio, \$16, el fiscal protector anota que «en la villa de Potosí es su corriente presio el de siete a ocho pesos» ANB -1755- 59: 7v), ropa de la tierra y paño de quito, lana de color -donde obtenía una doble ganancia obligando a las mujeres a que le pagaran con ponchos que él vendía en Potosí. Parece ser que esta entrega de lana para hilar y tejer ponchos comerciados fuera de la provincia, La Plata, Potosí y Salta, era más general y excedía la idea de los repartos para transformarse en otra forma de exacción (Cf. al respecto ANB -1755- 59: 25v, 26r, $34 \mathrm{v}, 43 \mathrm{v}, 61 \mathrm{r}$.).

\section{Otras exacciones}

Tejer gratuitamente para el gobernador no era la única obligación que éste imponía sobre la comunidad campesina atacameña. A los pastores les entregaba sus ganados para que éstos los pastorearan. $\mathrm{Si}$ se perdía alguna oveja o carnero de Castilla lo hacía pagar a precios excesivos y en caso de no pagar los encarcelaba (Cf. ANB -1755- 59: 24r, 33r, 42r, 51r y 59r.). Además, la comunidad entregaba al corregidor cada ocho días «pongos y mitayos»:

Los mitanes, obejeros, baqueros y muleros y pastores que todos se ocupan en este travajo de ocho a ocho días, y se mudan, sin mas paga, ni recompenza, que el maltrato, y que ni aun de comer se les da, sino que a su costa, se mantienen y sirben al dicho Corregidor, y que asi mesmo a la mitanes le an de dar, y que en esto se ocupan seis indios, y que de estos, es una muger sola, y los cincos son hombres que se ocupan en esto, y que asi mesmo al leñero por la leña que traen para dicho Corregidor no le paga, como así mesmo, al que trae pasto para sus mulas, la paga es con rigor, y los ainenasa con asotes que les dara en el rollo (ANB -1755- 59: 25r).

Se aprecia en este testimonio de Juan Rodrigo, como en el de otros testigos, una queja que tiene dos dimensiones. Por una parte, se denuncia crudamente el abuso y, por otra, se sugiere la absoluta falta de reciprocidad en los servicios que prestan al Corregidor, «ni aun de comer les da, a diferencia de los servicios prestados en la sociedad tradicional andina en que el kuraka a cambio del trabajo retribuía a la comunidad con chicha de maíz o de algarrobo, como probablemente sucedía en Atacama (Cf. al respecto Muna [1975]).

No tenemos ninguna referencia directa a las propiedades o tierras agrícolas asignadas o pertenecientes al Corregidor, pero sí sabemos que todas las comunidades encabezadas por los caciques de los ayllus estaban obligadas a rosar, sembrar y cosechar a cambio de coca. El mismo Juan Rodrigo señala:

Y que quando llega la ocasion de la siembra, los hase sembrar y trabajar sin pagarles su trabajo, y que ocupando en esto toda la comunidad hombres y mugeres que sus casiques de cada ayllo los lleva para este efecto apenas les da como cosa de tres libras de coca, para que toda la comunidad se reparta, y que los pobres yndios que no tienen asadones y otras herramientas para sembrar los alquilan a su costa con su plata y que de ocuparse en este trabajo, es por un dia en rosas y otro en sembrar toda la comunidad, casadas, solteras y viudas y que en coger la cosecha se ocupan, otros dos dias toda la comunidad en segar y trillar, y que tampoco les paga ni un quartillo conforme executa en la sierra (ANB -1755- 59: 25r-25v)

El dato interesante que señala Juan Rodrigo, es que algunos campesinos carecían de herramientas propias y tenían que arrendarlas para cumplir con este servicio comunitario al Corregidor.

En cuanto a los ingresos que el corregidor recibiría por este trabajo comunitario en sus tierras, probablemente predios ubicados junto a cada ayllu, solo tenernos un dato. Nicolás Lazo de la Vega encontró en el troje de Manuel Fernández Valdivieso 107,5 fanegas de trigo que quedaron depositadas en poder del gobernador Don Pedro Pachao y don Marcos Viveros para el caso que fuese necesario restituir a 
los demandantes con bienes del Corregidor (ANB -1755- 59: 19r-21r).

Otras exacciones tienen que ver con multas, embargos o castigos aplicados por el Corregidor y que, además de azotes y encarcelamientos, implicaban pago en especies o dinero valorado por este funcionario. Veremos sólo algunos ejemplos para no extender más este punto.

A un indígena llamado Roque, por no haber asistido a la Revisita a la que estaban citados, lo multó quitándole cinco vacas y veinticinco pesos, además de maltratarlo (ANB -1755- 59: 8r, 35r, 35v, especialmente $44 \mathrm{v}$ ).

$\mathrm{Al}$ cacique don Blas Bentura le quitó treinta y cinco libras de lana de vicuña, avaluándolas a dos pesos en circunstancia que aquél las tenía vendidas a cinco pesos la libra, también le quitó dos vacas lecheras, avaluándoselas en cuatro pesos cada una valiendo éstas ocho pesos. Blas Bentura además cometió u error que el Corregidor se lo hizo pagar muy caro. Se le escapó un español que traía prisionero por orden del Corregidor; por lo que fue azotado en una escalera «hasta sacarle pedasos de carne» (ANB $-1755-59: 2 v)$, junto con tenerlo durante cuarenta días en la cárcel, cobrándole, además, una suma de 140 pesos que le debía el español. Para cubrir parte de tal deuda, el Corregidor le quitó diversos objetos, incluido el vestuario y veinte pesos de plata (ANB -1755- 59: 2r/2v, 8v/9v, 27r/29v, 35v/36r, 37v, 45r/46r, 56). Sólo pudo salir de la cárcel cuando el cura bachiller don Bernabé Suleta se hizo responsable de la deuda y se comprometió a pagar por Bentura entre 105 y 150 pesos a cuenta de su sínodo (ANB -175559: 2v, 29v, 38r, 47r).

A otro indígena, Domingo Valdivieso, a quien el Corregidor acusó de estar amancebado, lo encarceló y le quitó nueve mulas con su madrina. Le sirvió de fiador para salir de la cárcel otro indígena, Lorenzo León (ANB -1755- 59: 30r, 38v, 47v, 56v).

A Domingo Quependur, en Olaros, acusado de trabajar unas minas, lo tuvo cuatro días en su toldo con un par de grillos y lo multó en veinticinco pesos. Cinco pesos los pagó en lana de vicuña y el resto en plata (ANB 59: 30r, 38v, 47v, 56v).

\section{El Alcalde Mayor de Minas y la expropiación de un venero de oro}

Este es un caso que aparece como único, pero que sin duda debe inscribirse entre los intentos fallidos de expropiación de bienes raíces indígenas. Acá se careció de toda sutileza, lo que unido a otras situacio- nes igualmente graves, acarreó la investigación de la Real Audiencia que intervino para corregir el hecho doloso obligando al Corregidor a devolver lo arrebatado y a pagar una indemnización por los daños.

De acuerdo a la información que entregaron los testigos, los hechos podrían ser los siguientes:

Balthasar Asencio, indígena atacameño, descubrió un venero de oro en Olaros (actualmente en territorio argentino, que estaba sujeto, al parecer, al gobierno indígena de Toconao. Como descubridor hizo los pedimentos legales ante el Alcalde Mayor de Minas, el corregidor Fernández Valdivieso, que no puso obstáculos y se lo concedió.

Durante tres años trabajó Balthasar Asencio en su venero, pero enterado el Corregidor de que la ley del lavadero era buena, mandó con un propio «de que suspendiese el trabajo de multa al miserable yndio y obedesio el mandado de su corregidor y dejó el trabajo de su pertenencia» (ANB -1755- 59: 38v/ 39r). Luego de esto el Corregidor se dirigió a Olaros:

Con bastante jente en su compañia llevando a los alcaldes y cobradores de tributos, motibado de su codicia a quitarle a dicho Baltasar Asencio los papeles en que se contenían sus pedimentos y licencias para quitarle de este modo al miserable yndio los ynstrumentos de su derecho y defensa juntamente a despojarlo del venero por su ynteres particular y mobido de su codicia puso en su lugar en posicion a un moso suyo nombrado don Martin de Sarria para que trabaje dicho de quenta del Corregidor (ANB -1755- 5939r)

Martín de Sarria trabajó por cuenta del corregidor más de dos meses. Llegó con treinta peones, pero quedaron en definitiva sólo quince, devolviéndose algunos porque no les pagaron jornal entero «sin a do reales y tres» y el resto se separó en busca del mineral. Algunos encontraban media onza y otros un cuarto. El Corregidor con amenazas «de que abia de mandar aprender y castigar a los miserables yndios y les quito la cortedad que adquirian» (ANB $-1755-59: 39 \mathrm{v})$.

Uno de los testigos, Juan Bisente, quien trabajaba con Balthasar Asencio cuando llegó el Corregidor a Olaros y que continuó trabajando como peón de Martín de Sarria, nos ofrece datos que permiten calcular el monto del oro extraído durante la primera fase de la usurpación:

Este declarante dise que hallaron con sus 
compañeros un clabo de metal de oro y lo cojio lo referido, don Martín y de la tierra de beneros labandolas todos los dias se saca quatro onsas algunas beses tres onsas y tres onsas y inedia, de suerte son sesenta dias lo que declara este declarante, de que duro el trabajo que por aqui se pueden hase la conjetura poniendo a tres onzsas uno con otro en los sesenta dias. Finalmente dise este declarante el clabo de metal de oro se Ilebo el referido chapeton don Martin que tendria poco más o menos quatro libras (ANB -1755-59: 48v).

Si consideramos que una onza equivale a 28,7 gramos, tres onzas diarias representarían unos 86,1 gramos, lo que multiplicado por sesenta días da un total de 5,166 gramos. Ahora bien, la libra equivale entre 400 y 460 gramos, usando la cifra más baja y multiplicado por cuatro, el clavo de oro no pasaría de 1.600 gramos. La suma de ambas cantidades indica que la producción de oro en esos dos meses fue de seis kilos setecientos sesenta y seis gramos.

Don Martín de Sarria huyó de Olaros con el clavo de oro, en su reemplazo Manuel Fernández Valdivieso envío otros cuatro españoles, cada uno con un grupo de indígenas que continuaron lavando oro por otros dos meses.

Pero, ¿qué pasó con Balthasar Asencio, el descubridor y poseedor legal del venero? Se presentó en Olaros ante el Corregidor para representarle su derecho. El Alcalde Mayor de Minas:

Sin oir razones le dio una buelta de golpes y patadas diciendo si le traya la plata de la multa y respondio dicho infelis Baltasar de que no tenia plata yndignado de esta respuesta bolbio a continuar con las patadas y lo mando poner a la carsel con un par de grillos» (ANB -175559: 40r)

La multa para Baltasar Asencio, hombre de «edad avanzada», fue de quinientos pesos. A cuenta de esa cantidad el Corregidor le quitó nueve mulas, cuarenta pesos en dinero y una libra y seis onzas de oro (ANB -1755- 59: 3v, 49r). Además le quitó cinco cajones de tierra cernida, que los testigos no aciertan a calcular su contenido en oro, dos vacas lecheras, una de las cuales mató en Olaros y la otra se la trajo a San Pedro, cuatro carneros de Castilla «que para su gasto lo mando matar» y seis costales de algarrobo (ANB -1755- 59: 3v/4r, 49v).
No terminaron acá los atropellos cometidos con Balthasar Asencio:

«Posteriormente aviendo berrido Balthasar asencio al Pueblo de Atacama, le quito nuevamente el Corregidor sinco onsas de oro, poniéndolo despues con un par de grillos en la carsel, donde lo mantubo treinta y nuebe dias». Nuevamente fue multado Balthasar Asencio en trescientos pesos y encarcelado, al verlo «padesiendo con su pricion en la carsel como tan piadoso teniendo lastima el cura don Bernabé Soleta le hiso obligacion para el seguro de su satisfaccion y con paga con plaso de siete meses ambos con este declarante (ANB -1755- 59: 49v).

Al término de los siete meses, don Bernabé Suletta pagó 250 pesos. Lorenzo León que se había comprometido por cincuenta pesos para completar los trescientos, fue obligado por el Corregidor a pagar antes de que se cumpliese el plazo; como el fiador no tenía dinero en el momento, le quitó tres mulas nuevas y mansas avaluándoselas en 18 pesos cada una, habiéndolas pagado a 25 pesos Lorenzo León cuando las había adquirido (ANB -1755- 59: 41r).

La Real Audiencia ordenó devolver a Balthasar Asencio sus pertenencias legales; en relación a los otros daños, el Fiscal protector recomendó que por todos los cargos:

Le pague dicho corregidor la cantidad de doscientos sinquenta y quatro pesos con más sinco mulas competentes, que se han de entregar en aquella provincia de que y gualmente se le a de remitir al fiscal protector certificación de dicho cura (ANB -1755- 59: 74r/81r).

También se le dieron cuarenta pesos corriente, que le correspondía de la prorrata de los 150 pesos en que se evaluaron los costos de los recursos que hicieron contra el Corregidor.

\section{Las redes de alianzas del poder local.}

La acción del Corregidor de Lipez Laso de la Vega, enviado por la Real Audiencia a investigar las denuncias, y los informes del fiscal protector, trataron de poner atajo los abusos excesivos del Corregidor. No obstante, al examinar las sentencias propuestas, causa extrañeza la debilidad de las sanciones im- 
puestas. El argumento del fiscal es que los indígenas no pueden permanecer en La Plata y Manuel Fernández Valdivieso ha convenido con ellos un arreglo indemnizatorio. Aunque todos los delitos de abusos de autoridad estuvieron sobradamente comprobados, el arreglo fue beneficioso para el Corregidor, pues habiéndose comprometido a pagar mil cien pesos, con esta suma no alcanzaba a pagar los daños y pérdidas materiales que le había ocasionado a los indígenas.

También este arreglo permitía a Manuel Fernández Valdivieso volver a ocupar su cargo en la Provincia de Atacama, debiéndosele devolver:

las ciento y siete fanegas, y media de trigo, que oficiosamente se le embargaron por el comisario, conputandole el lugar de pena por cualquier asumpto criminal, que contra el pueda resultar; no sólo las exsibidas cantidades de pesos, que sin concluiente conbensi-miento ha desenvolsado libremente, sino tambien los manifiestos atrasos, penalidades, y menoscabos, que asta el presente, es constante se le ha inferido, todo lo que abre margen a la coniniserasion, para que tenga lugar la equidad de V.A., no se pueda despues nuebamente mober en juicio alguno (ANB -1755- 59: 74v-75r)

Para este miembro de la burocracia regional, el Corregidor había sufrido «manifiestos atrasos, penalidades, y menoscabos», por los que había tenido que desembolsar «exsibidas cantidades de dinero», sin que éstas estuvieran justificadas en «concluiente conbensimiento». La notoria diferencia que se observa entre esta relación y la que anteriormente se había entregado a propósito de los autos de brujería, en los que se había denunciado la «malicia» con la que actuaba el Corregidor, bien podría corresponder a las alianzas que se formaban entre algunos segmentos de la burocracia central y los miembros de los poderes locales coloniales, que podrían extenderse también entre los propios corregidores.

El Fiscal Protector que había solicitado la sumaria contra el Corregidor, sostuvo que durante la sumaria hubo un conjunto de obstáculos que impidieron la reunión de mayores antecedentes que inculparan al Corregidor de Atacama. El Fiscal sostuvo, además, que el Corregidor de Lipez actúo con poco celo e integridad, por lo que sugirió una cierta complicidad entre éste y Fernández Valdivieso:

que dicho comisario hiso con no poco enpeño artificio que saliese el Corregidor a la corta distancia de dos leguas de el lugar donde se estavan actuando las diligencias, lo que aparece también de el proceso con el premeditado designio que con efecto se verifico de que los ynterpretes y demás ytnbentores le diesen puntualmente quenta al Corregidor como que era de su faccion de todo quanto se obrava para poner no solo los correspondientes reparos sino tavnbien para vincular en el aprecio de el capitulado un rencor y enemiga para con los actores y testigos (ANB -1755- 59: 7r).

Aunque los datos impiden profundizar, en la alianza que hemos supuesto entre el Corregidor y algunos segmentos de la burocracia regional, como entre los propios corregidores, aquélla es notoria entre quienes conformaban la red de poder local. Saignes (1991) ha señalado que los espacios locales fueron constantemente disputados por el Corregidor, el cura y los caciques, generándose en muchas ocasiones alianzas que permitían redistribuir las cuotas del poder local.

Atacama no estuvo exenta de aquellas alianzas que derivaron, en algunos ocasiones, en una manifiesta complicidad entre quienes ejercían el poder político y religioso en la Provincia. Hacia 1755 esta situación fue denunciada por el Fiscal protector quien sostuvo que era «antigua ydea entre Corregidores y Curas el prestarse mutuamente auxilios en casos de la presente contingensia sobsteniéndose recíprocamente unos a otros en alternativa correspondensia» (ANB -1755- 59: 7r). La contingencia, a la cual el Fiscal hacia referencia, eran las circunstancias que habían rodeado a la sumaria ordenada por la Audiencia para investigar las acusaciones dirigidas por los indígenas al Corregidor. De acuerdo al informe del Fiscal, el cura Juan Antonio Terán:

vino desamparando su Curato en tiempo de la sumaria al lugar donde se rexcivia, a estorvar con su respeto por complaser al Corregidor la livertad de los indios deponentes pues amendrentados de el temor que les yncutia expresandoles, que el capitulado Corregidor avia de permaneser en el empleo y que entonces los avia de castigar y haorcar se v[e]ian comprimidos sin poder testificar quanto savian procurando antes por lesongerle desfigurar en no pequeña parte los hechos que les constava (ANB -1755- 59: 6v). Este tipo de alianzas fue denunciado, años más 
tarde, por el Gobernador de Toconao quien sostuvo que los curas y corregidores habían sometido a los indios a continuas molestias, levantandoles testimonios, que ocasionaron el alboroto del Pueblo («Representación de Pascual Guacasus, gobernador de Atacama, sobre que el Corregidor de dicha provincia don Manuel de Baldivieso le hace cargo del tributo de catorce indios» ANB -1757- 50:1 v-2r).

Algunas autoridades y miembros de la comunidad indígena también tuvieron una suerte de complicidad con el Corregidor de Atacama. A pesar de las pocas atribuciones políticas, administrativas y judiciales, de los dispositivos indígenas (caciques, gobernadores, alcaldes mayores, alguaciles y jueces) éstos fueron indispensables para el actuar del Corregidor. Muchas veces estos cargos no eran representativos de los intereses indígenas y quienes lo ejercían no podían pretextar un derecho hereditario sobre su ejercicio. A diferencia de otros cacicazgos que hemos estudiado, en los que el cargo de cacique gobernador era hereditario, en Atacama, en esta época, la situación es notablemente distinta, pues su designación pasó a ser una atribución arbitraria del Corregidor (Hidalgo 1996: 177). En un alegato por los derechos al cacicazgo de San Pedro pretextados por Pedro Sebastián, uno de los testigos declaró que «así a este modo se hiban alternando a otros vezinos en el mermo empleo, sin que hayga simil de que hayga caciques por erenzia» (ANB -1758- 64: 12v). Este mismo testigo señalaba que desde tiempos inmemoriales eran los Corregidores quienes tenían la facultad de nombrar caciques. La misma dependencia se observaba en los otros cargos indígenas, como el de alcalde mayor, alguaciles y jueces.

Hemos señalado también que en algunos momentos, como es el caso de la acusación de brujerías contra Diego Cruz Moro, podían coincidir los intereses del Corregidor con el de ciertas autoridades indígenas. Los alguaciles y jueces fueron también dóciles instrumentos en la detención y castigos que padecieron los implicados en los procesos y causas seguidos por el corregidor contra algunos indígenas.

Pero esta última situación no puede extenderse al conjunto de los indígenas que formaban parte de la estructura política indígena colonial. Fue Pedro Sebastián, quien ocupó durante algún tiempo el cargo de alcalde mayor de San Pedro de Atacama, el que sirvió como apoderado de Francisca Elvira en la solicitud que ésta hizo al Fiscal Protector de la Audiencia de La Plata para que el Corregidor Fernandez Valdivieso respondiera de todos los perjuicios que ella y su familia habían sufrido (ANB -
-1754- 58: 25r). Aunque Pedro Sebastián había sido alcalde mayor «por el señor don Manuel Fernandez Valdivieso» (ANB -1758- 64: 10v), parece ser que los atacameños más perjudicados por el Corregidor tenían en él a una figura respetuosa de la moralidad comunitaria. Lo que explica que, aun cuando Pedro Sebastián no ostentaba el mencionado cargo, Francisca Elvira lo haya nombrado su representante apoyada en el hecho incuestionable que «sabe todos los trabajos castigos que a echo el Señor General don ManuelFernaiides Valdibieso ynjustaumente» (Ibíd.). Tiempo más tarde, fue él quien encabezó al grupo de atacameños que acusó al Corregidor ante la Real Audiencia por los delitos que más arriba hemos señalado.

A pesar de las amenazas proferidas por el Corregidor para quienes intentaran demandarlo ante la Real Audiencia, Pedro Sebastián y Juan Rodrigo emprendieron secretamente el camino a Chuquisaca, portando cartas de todos los afectados. Enterado el Corregidor, ordenó a un grupo de mestizos la detención de ambos indígenas. Juan Rodrigo logró huir, pero Pedro Sebastián fue detenido y sufrió el encierro y los azotes por varios días, hasta que los caciques lograron que el Corregidor lo dejara libre (ANB -1755- 59: 6v).

Que fueran mestizos los que detuvieron a Pedro Sebastián, ¿permite pensar que el Corregidor, quien hasta entonces había ejercido un abusivo control sobre la población indígena, temía una recomposición de las solidaridades comunitarias que se expresaba en este intento corporado por llevarlo a juicio? No tenemos la suficiente evidencia documental como para determinar la percepción que el Corregidor tuvo durante este período, pero creemos que es posible que preocupaciones de este tipo hayan ensombrecido su apacible existencia.

El encierro y los castigos que Pedro Sebastián había padecido, junto con las presiones del cura y los vecinos de San Pedro que advertían que cuando el Corregidor regresara castigaría con todo su poder a los acusadores, no le impidieron asumir la acusación y la presentación de testigos en la sumaria de 1755 ordenada por la Real Audiencia. Si bien las intenciones de Pedro Sebastián pudieron derivar de una asumida convicción sobre el injusto proceder del Corregidor, lo que fue incluso percibido por algunos de los indígenas que sufrieron directamente la opresión de éste, ¿es posible que ellas se remitieran a una intención no confesada como la de crearse una base de prestigio lo suficientemente sólida como para reclamar algún lugar de preeminencia en el espacio 
indígena colonial? Después de todo, en el período que estudiamos, la autoridad indígena atacameña no parece haber estado asentada en una suerte de tradición que la legitimara. Pedro Sebastián bien pudo tener la intención de establecer una red de aliados que le ayudasen a lograr un reconocimiento en el débil espacio de las autoridades indígenas.

En 1758 solicitó a la Real Audiencia que se le restituyeran las tierras que, de acuerdo a su testimonio, le pertenecían a él y a sus hermanos y de las cuales habían sido injustamente despojados. Durante un poco más de un año, Pedro Sebastián anduvo fugitivo «sin mas havitacion de andar escondido entre los serros y quebradas peresiendo de hambre a los riesgos de los tiempos a que me a sujetado los miedos con que que me hallo» (ANB -1758- 64: 1v). ...I había huido de San Pedro por temor a las violencias que había padecido en manos de un mestizo, Pascual Sanción, quien ocupaba en ese entonces el cargo de cobrador de tributos y cacique. En la representación que hace a la Audiencia, Pedro Sebastián se presenta a sí mismo como:

Hijo legitimo del Governador Don Marcos Lorenzo casique principal del pueblo de San Pedro de Atacama Alta... y digo que mis mayores Padres y abuelos desde ynmemorial tiempo pusieron en el empleo de casicazgo en el ayllo de Solo sin que nadie inpidiese su legitima posesion (ANB -1758- 64: 1.v)

Ninguno de los testigos que Pedro Sebastián presentó, avaló sus pretensiones de usufructuar las tierras que le correspondía a los caciques. Frente a las pretensiones de legitimar su derecho en el «ynmemorial tiempo», los testigos sostuvieron que el cargo era alternado no existiendo caciques por herencia, por lo que las tierras eran usufructuadas por quienes detentaban el cargo. Y esta era una situación que existía desde tiempos inmemoriales junto con la facultad del corregidor para nombrar cacique (ANB -1758- 64: 12r).

Después de reunidos los testimonios y declaraciones, la Real Audiencia reprendió a Pedro Sebastián advirtiéndole que si volvía en otra ocasión a pretextar algún derecho «se le impondrán las penas que sean convenientes a su moriferacion y castigo las que por ahora no se le imponen usando de conmiseracion» (ANB -1758- 64: 20v).

La prolongada ausencia de Pedro Sebastián pudo haber incrementado el temor entre sus aliados, por lo que se vieron obligados a quitarle su apoyo al punto de no avalar sus pretensiones al cacicazgo.

\section{OBSERVACIONES FINALES}

En más de una ocasión se ha reiterado la dificultad para emprender, dada la carencia de fuentes documentales, estudios históricos o etnohistóricos en el área de Atacama. Algunos equipos multidisciplinarios han superado estas limitaciones documentales, recopilando, ya sea en el trabajo de archivos o en el trabajo de campo, los materiales necesarios para el diseño de estrategias de investigación que han incrementado la información y las problemáticas de estudios del área atacameña.

En esta perspectiva, el presente trabajo ha profundizado en el estudio de algunos aspectos de la realidad colonial de Atacama. Hace algunos años uno de nosotros utilizó la misma documentación de este artículo para determinar las fases y el esquema de inestabilidades políticas que antecedían a la rebelión indígena de 1781 en el área de Atacama (Hidalgo 1982). La etapa que va entre 1749 a 1757 llamó la atención por encontrar en ese período un buen corpus documental para reconstruir la primera etapa del esquema de inestabilidades. En esa ocasión no era nuestro objetivo entrar a detallar cada una de las etapas. Con este artículo esperamos haber aportado mayores detalles para el período 1749-1755. Específicamente, nuestro interés ha estado centrado en el estudio de la brujería colonial en Atacama, las complejas relaciones de poder que aparecen durante el proceso por brujerías, las alianzas y los conflictos que se dan al interior de la sociedad colonial, las características que asumieron el control político y la expoliación colonial, entre otros.

No obstante, el proceso por brujerías fue el tema rector de nuestro artículo. Sobre esto son necesarias algunas aclaraciones. Primeramente, una cuestión metodológica que ha ganado terreno en la pragmática de investigación etnohistórica. Esta tiene relación con la dificultad epistemológica de aislar las realidades indígenas presentes en la documentación colonial. A través del texto hemos hecho referencia a la curandería, la brujería y la hechicería como si se tratara de un mismo fenómeno. Esta confusión ha sido intencional, pues hemos querido acentuar las propias confusiones conceptuales presentes en la documentación y que arrancan del hecho colonial que ha redefinido las prácticas indígenas (como es el caso de las desarrolladas por los curanderos atacameños) dentro de un conjunto de objetos (brujerías, pactos con el demonio, supersticiones, idola- 
trías) que representan una desviación con respecto al sistema de dominación colonial.

Las facultades de los curanderos para hacer y deshacer daños únicamente provendrían de un pacto con el Demonio, por lo que este tipo de prácticas podrían, potencialmente, subvertir el orden social. A partir de este hecho se operó un desplazamiento en la figura del curandero, quien fue representado de acuerdo a los estereotipos del brujo o hechicero, $\mathrm{y}$, por tanto, fue inscrito en el ámbito de aquellos individuos considerados como peligrosos para el cuerpo social. Para el poder local atacameño, la presencia de estos brujos evidenciaba la ausencia de un sistema de control eficaz que sujetara a los indios y que impidiese la reproducción de las supersticiones y de las idolatrías, facilitada también por la acción del Demonio.

Las brujerías, las supersticiones y las idolatrías constituían un mismo espacio que reclamaba tanto la intervención del poder como su penetración en aquellos espacios que, al parecer, habían coexistido al margen de las relaciones de poder coloniales. De este modo, la apropiación de los cuerpos nativos y de las tácticas punitivas desplegadas para el disciplinarniento y transformación de los mismos, encuentran su racionalidad en una economía discursiva que tiende a justificar su intervención y su penetración en espacios constituidos por «hombres como mujeres viciados».

Esta lógica fue manipulada por el Corregidor para ejercer una apropiación de los recursos y los bienes de subsistencia indígena, a través de mecanismos como el reparto forzado de mercaderías, el control arbitrario de la oferta y la demanda, la usurpación de tierras, etc. Pero tales actuaciones del Corregidor encontraron resistencia entre los miembros de la comunidad que consideraron como injustas sus medidas por cuanto éstas sobrepasaban los límites de una moralidad sancionada, por las autoridades coloniales y por la tradición indígena, y que debía regir las relaciones tanto en el interior de la comunidad como las que sus miembros establecían con los representantes del poder real.

En los autos del corregidor y en la relación del fiscal hemos demostrado la presencia de distintas valoraciones de la brujería, que señalan las diferentes perspectivas de un mismo fenómeno entre funcionarios de la burocracia central y los miembros del poder local. En su conjunto, ambas valoraciones contienen una representación del indio: una lo considera un sujeto pasivo, cuyo único delito es el de haber nacido «bajo influxo de desdichados»; la otra lo considera un sujeto activo, en tanto se trata de sujeto viciado. También ambas suponen diferentes mecanismos de control y de transformación de los indios: el conocimiento de la doctrina cristiana, para el Fiscal y la Audiencia; el uso de tácticas punitivas (destierro, azotes y otros), para el Corregidor.

Aunque no se discute la realidad de la brujería y del pacto con el Demonio, el fiscal restó importancia a la acusación de brujería por carecer de pruebas sólidas y por considerar que ella sólo incrementaba la opinión que los indios se hallaban sometidos al despotismo y la tiranía del corregidor.

En el mundo indígena la brujería formaría parte de un sistema de interpretación de los desequilibrios comunitarios e individuales, al que se ha agregado la carga demonológica europea. De este modo, la representación colonial del brujo se elaboró a partir de los elementos demonológicos y de la propia ambigüedad que el curandero tenía en el mundo indígena.

Otro elemento, que consideramos necesario resaltar, es el entramado de conflictos y alianzas que se pueden evidenciar entre los distintos componentes del poder local atacameño. Una mayor evidencia documental bien podría profundizar en esta problemática y que, de todas maneras, vuelve a resurgir, décadas más tarde, en el contexto de la rebelión de Tupac Amaru.

Concluiremos este trabajo señalando que, si bien hemos acentuado la vinculación entre el proceso de brujerías y las formas de control político y de apropiación de los cuerpos nativos, ello no impide que puedan ser estudiados a la luz del alcance que pudo haber tenido el proceso de evangelización en Atacama, y sobre el cual, últimamente, se ha hecho una importante y sustancial contribución (Cf. Castro 1997).

\section{SIGLA}

ANB Archivo Nacional de Bolivia, Sucre.

\section{FUENTES DOCUMENTALES}

«Autos seguidos por los indios del pueblo de Tacamas (San Pedro de Atacama) provincia de Atajama, contra don Manuel Fernández Valdivieso, sobre varios maltratamientos» ANB -1754- $\mathrm{N}^{\circ} 58,26$ fojas.

«Autos seguidos por los indios del pueblo de Atacama contra el corregidor Mariano Fernández Valdivieso, por varios maltratos» ANB -1755- $\mathrm{N}^{\circ}$ 59, 82 fojas. «Representación de Pascual Sebastián Guacasus, 
Governador de Atacama, sobre que el Corregidor de dicha provincia don Manuel de Baldivieso le hace cargo del tributo de catorce indios» ANB -1757- $\mathrm{N}^{\circ}$ 50,6 fojas.

«Representacion de Pedro Sebastian, indio casique del Pueblo de San Pedro de Atacama, sobre que un mestizo, llamado Pascual Sandon, se ha apoderado del casicasgo y como consecuencia haber sembrado en tierras de su propiedad» ANB -1758- $\mathrm{N}^{\circ}$ 64, 20 fojas.
«Instrucción y ordenanzas hechas por el Virrey don francisco de Toledo para los corregidores de indios, 1574» ANB -1764- Expedientes coloniales $N^{\circ} 131$ : 80-123.

«Libro de Bautismo de San Pedro de Atacama, 17371783». Museo Arqueológico Rev. P. Gustavo Le Paige.

\section{BIBLIOGRAFIA}

AGRIMI, J.; CRISCIANI, Ch.; Savoir médical et anthropologie 1993 religieuse. Les répresentations et les fonctions de la vetula. En: Anuales E S C 5: 1281-1308.

ARGUEDAS, José María; Indios, mestizos y señores. Editorial 1987 Horizonte, Perú

ARRIADA, Pablo José; Extirpación de la idolatría en el Pirú. 1968 En Crónicas peruanas de interés indígena, Francisco Barba editor. BAC vol. CCIX. Ediciones Atlas, Madrid

BERNAND, C. y GRUZINSKI S.; De la idolatría. Una arqueolo1992 gía de las ciencias religiosas. México: Ed. Fondo de Cultura Económica.

CAMPAGNE, Fabián. El largo viaje al Sabbat: la caza de bruja en 1997 la Europa moderna. En: Estudio preliminar a Castañega Tratado de las supersticiones y hechicerías UBA, Argentina

CASTRO, Victoria. Huacca Muchay. Evangelización y religión

1997 andina en Charcas Atacama la Baja. Tesis para Optar al Grado Académico de Magíster en Historia, Universidad de Chile (Inédita).

CASTRO, Victoria y MARTINEZ, José Luis. Poblaciones indí1993 senas de Atacama. En: Jorge Hidalgo et al. (Eds.) Culturas de Chile. Etnografía. Sociedades indígenas contemporáneas y su ideología. Sociedad Chilena de Arqueología. Santiago, Chile.

CHAUNU, Pierre. Sur la fin des sorciers au XVIIe siècle. En: 1969 Anuales E S C 4: 895-911.

FLORES A., Francisco. El diablo en España. Alianza Editorial, 1985 Madrid, España.

FLORES E., Javier. Hechicería e idolatría en Lima colonial (Siglo 1991 XVII). En: Urbano (comp.) Poder y violencia en los Andes. Debate Andino $\mathrm{N}^{\circ}$ 18, Perú, Centro de Estudios Regionales Bartolomé de las Casas.

FOUCAULT, Michel. EI nacimiento de la clínica. Una arqueolo1966 gía de la mirada médica. México: Editorial Siglo XXI.

$1994 \quad$ Vida de los hombres infames. Ensayos sobre dominación y desviación. España: Ed. La Piqueta.
GAREIS, Iris. Una bucólica andina: curanderos y brujos en la cos1994 ta norte del Perú (Siglo XVIII). En: Millones y Lemlij (ed.) En el nombre del Señor. Shamanes, demonios y curanderos en el norte del Perú. Biblioteca Peruana de Psicoanálisis, pp 211-230.

GIRARD, René. El Chivo Expiatorio. Ed. Anagrama, España. 1986

GOLTE, Jurgen. Repartos y rebeliones. IEP, Lima. 1980

HIDALGO, Jorge. «Incidencias de los patrones de poblamiento 1978 en el cálculo de la población del Partido de Atacama desde 1752 a 1804. Las revisitas inéditas de 1787-1792 y 1804» en Estudios Atacameños, 6: 53-111.

1982 «Fases de la rebelión indígena de 1781 en el corregimiento de Atacama y esquema de la inestabilidad política que la precede 17491781. Anexo dos documentos inéditos contemporáneos» en Chungará 9: 192-246.

1984 «Complementariedad ecológica y tributo en Atacama,1683-1792» en Estudios Atacameños, 7:422-442.

1984 «Descomposición cultural de Atacama en el siglo XVIII: lengua, escuela, fugas y complementariedad ecológica». Simposio Culturas Atacameñas $44^{\circ}$ Congreso de Americanistas, Universidad del Norte, Antofagasta.

1987 «Tierras, exacciones fiscales y mercado en las sociedades andinas de Arica, Tarapacá y Atacama, 1750-1790». Olivia Harris et al. (comp.) La participación indígena en los mercados surandinos. Estrategias y reproducción social, siglos XVI a XX CERES, La Paz, Bolivia, pp. 193-231.

1996 Rebeliones andinas en Arica, Tarapacá y Atacama, 1770-1781. En: Charles Walker (comp.) Entre la retórica y la insurgencia: las ideas y los movimientos sociales en los Andes, siglo XVIII. Centro de Estudios Bartolomé de las Casas, Perú. 
HIDALGO, Jorge y MANRIQUEZ V iviana. Mercados y etuicidad: 1992 lecturas de la revisita de Atacama de 1683 en Estudios Atacamelios, 10:149-167.

LANNEC, Hurbon. El bárbaro imaginario. Editorial Fondo de 1994 Cultura Económica, México.

LANGTON, Édouard. La démonologíe. Étude de la doctrine 1951 juive et chrétienne son origine et son développement. Payot, Paris.

LEVI -STRAUSS, Claude. Antropología estructural. Altaya, 1995 España.

MALENGREAU, Jacques. Desgracias, maleficios y remedios: 1994 equilibrio y divisiones en los Andes del Utcubamba. En: Millones y Lemlij (ed.) En el nombre del Señor. Shamanes, demonios y curanderos en el norte del Perú. Biblioteca Peruana de Psicoanálisis, pp 253-283.

MARTINEZ, José Luis. Asentamientos y acceso a recursos en 1990 Atacama (S. XVIII). Serie Nuevo Mundo: cinco siglos $\mathrm{N}^{\circ} 5$ Depto. de Ciencias Históricas, Universidad de Chile, pp. 1361.

MICHELET, Jules. La bruja. Un estudio de las supersticiones 1987 en la Edad Media. Akal, Madrid.

MILLAR, René. Inquisición y sexualidad: conductas y actitudes 1996 a través de los papeles del tribunal de Lima 1570-1818. En Actas ele la VII Jornada Nacional ele Historia Regional ele Chile Departamento de Historia, Universidad de Chile.

MILLONES, Luis. Religión y poder en los Andes: los Curacas 1976 idólatras de la Sierra Central en Primera Jornada del Museo Nacional de Historia Lima, Perú.

1984 Shamanismo y política en el Perú colonial: los curacas de Ayacucho. En: Histórica Vol. III, 2: 131-148.

MORENO C., Alfredo. El corregidor de indios y la economía 1977 peruana en el siglo XVIII. Madrid: Consejo Superior de Investigaciones Científicas.

MURRA, John. Formaciones económicas y políticas del mun1975 do andino. IEP; Lima, Perú

NÚÑEZ, Lautaro y DILLEHAY, Tom. Movilidad giratoria, armonía social y desarrollo en los Andes Meridionales: Patrones de tráfico e interacción económica. Universidad Católica del Norte, Antofagasta. Chile.
SAIGNES, Thierry. Lobos y ovejas: formación y desarrollo de los 1991 pueblos y común en el Sur Andino. En S. Moreno y F. Salolnon (comp.) Reproducción y trasnformación de las sociedades andinas $\mathrm{T}$. II

SALOMON, Frank. Culto a los ancestros y resistencia frente al 1988 Estado en Arequipa entre los años 1748 y 1754. En: Steve Stern (comp.) Resistencia, rebelión y conciencia campesina en los Andes. Siglos XVIII al XX Instituto de Estudios Peruanos, Lima, Perú. pp. 148-163

SANCHEZ, Ana. Mentalidad popular frente a ideología oficial: el 1991a Santo Oficio de Lima y los casos de hechicería (Siglo XVII). En: Urbano (comp.) Poder y violencia en los Andes. Debate Andino $\mathrm{N}^{\circ} 18$, Perú, Centro de Estudios Regionales Bartolonlé de las Casas.

1991b Amancebados, hechiceros y rebeldes (Chancay, siglo XVII). Archivos de Historia Andina $\mathrm{N}^{\circ} 11$, Centro de Estudios Regionales Bartolomé de las Casas, Perú.

SANCHEZ, José. Cuerpo y enfermedad en las representaciones 1992 indígenas ele los Andes. En: Defossez et al. (ed.) Mujeres de los Andes. Condiciones de vida y salud. Taller Francés de Estudios Andinos- Universidad Externado de Colombia, pp. 61-79.

SILVERBLATT, Irene. Luna, sol y brujas. Géneros y clases en $1990 \quad$ Ios Andes coloniales. Archivos de Historia Andina $\mathrm{N}^{\circ} 10$, Centro de Estudios Bartolomé de las Casas, Perú.

TORD, Javier. «El corregidor de indios del Perú: Comercio y 1974 tributos». Historia y Cultura $\mathrm{N}^{\circ}$ 8, revista del Museo Nacional de Historia, Lima.

VAN KESSEL, Juan. La senda de los Kallawayas. CIDSA, 1995 Perú.

YAURI M., Marcos. Brujos y demonios en el imaginario de An1994 cash. En: Millones y Lemlij (ed.). En el nombre del Señor. Shamanes, demonios y curanderos en el norte del Perú. Biblioteca Peruana de Psicoanálisis, pp. 231-252. 
